\title{
Boaventura De Sousa Santos: \\ El ineludible compromiso de la razón postmoderna
}

José Ramón Catalán

Departamento de Filosofía

UCA, San Salvador

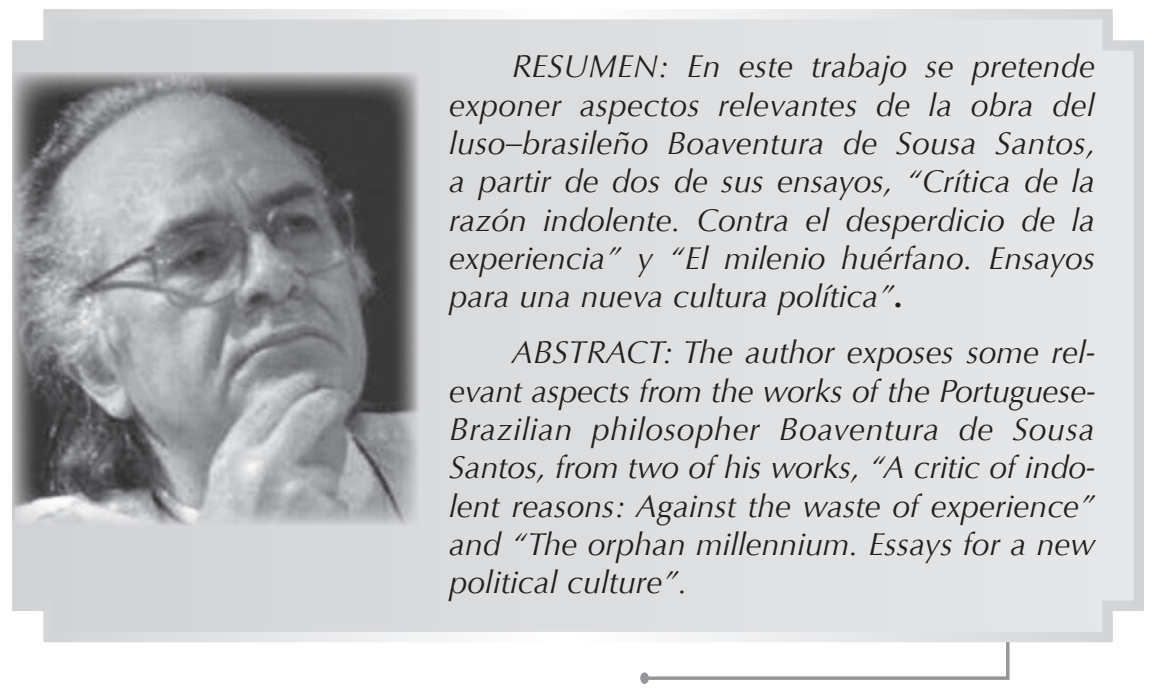

Quisiera dedicar lo bueno que haya en estas líneas a ese insobornable intelectual, crítico lúcido de la economía "ortodoxo-académica", Francisco Ibisate. Dicen que la mala hierba nunca muere; tú fuiste una demostración de que la buena, tampoco. Habrá, pues, que seguir dando guerra pero, eso sí, con sentido del humor. 


\section{Introducción}

n este trabajo se pretende ex- poner más o menos pormenori—zadamente una parte, quizá la más importante, de la obra del luso-brasileño Boaventura de Sousa Santos. Más en concreto, se hará referencia a dos de sus ensayos: "Crítica de la razón indolente. Contra el desperdicio de la experiencia"1 y "El milenio huérfano. Ensayos para una nueva cultura política" $^{\prime 2}$. Dado que su producción intelectual se inscribe de pleno en lo que podríamos Ilamar filosofía latinoamericana, hemos creído oportuno no entrar directamente en ella en esta Introducción sino dar un pequeño rodeo aprovechando algunas sabias reflexiones de Raúl Fornet Betancourt pues, como se intentará mostrar, las ideas del filósofo cubano van a ser ampliamente asumidas y desarrolladas por el Profesor Santos. Vamos, pues, con Fornet.

En 1992, Raúl Fornet Betancourt publicó una colección de artículos - "Estudios de Filosofía Latinoamericana $^{\prime \prime}$ - en los que muestra entre otras cosas las dificultades enormes de un pensamiento que no consigue abrirse paso, que no encuentra su acomodo, debido al peso que todavía arrastra del legado europeo. Y esto no es baladí o carente de importancia, porque como bien apunta Fornet, "desde una perspectiva filosófica resulta claro que el problema que realmente se debate en el fondo no es otro sino el de- cisivo de la dignidad ontológica y antropológica de América latina" $\left(\right.$ p.15) ${ }^{4}$. ¿Y dónde estriba el problema? Tal y como se apuntaba "la cultura latinoamericana se presenta como problemática porque refleja en sí la relación conflictiva entre la herencia cultural indígena y la europea" (p. 16). Y entonces, ¿desde dónde debemos definirla? "Para los latinoamericanos esta pregunta fundamental se convierte en un verdadero dilema, el cual conduce a posiciones extremadamente opuestas. Por una parte, se plantea la alternativa de la América indígena (...); por otra, se mantiene con igual seguridad el convencimiento de que la América nativa, como dijo Hegel, ha sucumbido al empuje del espíritu europeo" (p. 16). Cabría hablar de "mestizaje cultural", pero ¿en qué consiste? ¿No terminará una cultura siendo una vez más fagocitada por otra? Pero por otro lado, al proponer Fornet una filosofía auténticamente latinoamericana, es decir, que bebe en su propio pozo, ¿no estará cayendo en particularismos o relativismos? ¿Dónde está esa universalidad de la ha presumido el pensamiento europeo? Fornet es tan consciente de esa acusación, que nos advierte de que:

"L a articulación de una filosofía auténticamente latinoamericana llevará consigo probablemente el riesgo de un período de incomprensión o de grandes dificultades de comunicación con filósofos de otras latitudes, particularmente con los europeos. Sin embargo habrá 
que correr el riesgo, pues ahí se juega la posibilidad de afirmar que nuestra filosofía no habla una lengua aprendida, sino propia; que por consiguiente ninguna lengua ni cultura pueden pretender monopolizar las posibilidades de expresión filosófica" (p. 23).

$Y$ es que el primer paso que debe dar la filosofía latinoamericana es desenmascarar el eurocentrismo disfrazado de universalismo y esto trae gravísimas consecuencias porque entonces habrá que pensar desde lo Otro y no ya desde lo Mismo. Este párrafo, de claro corte benjaminiano, es crucial:

"Desde el margen, desde el "afuera" ${ }^{5}$ que genera esa cultura alejada de los centros tradicionales de producción filosófica, se logra una perspectiva que permite tener acceso a la filosofía desde lo que podríamos llamar el reverso de su historia oficial, de su vertiente occidental, para juzgarla e reinterpretarla como una forma de reflexión cuyas categorías, conceptos y racionalidad, en suma, no son entidades desencarnadas, sino resultados ligados a una determinada vida cultural y cuya universalidad, por consiguiente, está en el mejor de los casos, situada culturalmente y es, en cuanto tal, regional hasta cierto punto. Desde la culturas marginales la totalidad de la cultura dominante se destotaliza, se quiebra en su dialéctica centrífuga y se reubica como un momento de lo universal, justo porque se ha experimentado que no es la encarnación de lo universal" (p. 26).
En resumen, como puede verse, la gran tarea es encontrar ese espacio, ese "desde dónde" se debe pensar para plantear la pregunta por una filosofía latinoamericana en términos que permitan realmente el acceso a lo preguntado. "Ese "desde dónde", que está fuera del horizonte definido por la racionalidad de tipo europeo, es ciertamente lo ajeno, lo otro, lo "bárbaro", como diría Dussel"(p. 29) ${ }^{6}$.

Ya sabemos qué ha ocurrido con la universalidad, pero ¿qué hay de la razón? Tras lo afirmado hasta aquí ya podemos adivinar que será un tipo distinto de razón la que aquí se abordará. Entre otras cosas porque no hay razón en abstracto, "la razón está afectada sustancialmente por el hecho bruto de su existencia fáctica; la razón es siempre razón del hombre; éste es a su vez siempre un hombre concreto que vive y hace su razón en contextos dados"(p. 58). Por tanto facticidad e historicidad son las notas constitutivas de esta nueva razón que entra en escena. Pero hay algo más y es que esta nueva razón es multifacética. Podría objetarse que ya la Ilustración, siguiendo a Kant, ya puso de manifiesto esto al distinguir entre una razón teorética, una práctica y una estética, pero como luego se verá, esto no se tradujo en nada. Pero volvamos con Fornet Betancourt y su multifacética razón:

"La razón, por tanto no sólo es racional de diversas maneras, sino que tiene modos o posibilidades de realización concreta que escapan 
al horizonte de lo racional en cualquiera de sus formas. La racionalidad, entendida incluso como estructura formal sintetizadora de la pluralidad en que la razón puede ser racional, no es la única figura de la razón. La racionalidades más bien una dimensión, una vía, entre otras de la razonabilidad de la razón." (p. 58)

Sería bueno no perder de vista el final de la última frase, "razonabilidad de la razón" porque desde aquí podemos comprender que Fornet va a apostar precisamente por la "trans-racionalidad".

Si la razón es histórica, fáctica y multifacética es porque se halla enraizada en la realidad y esto le permite a Fornet Betancourt alejarse de cualquier filosofía de corte idealista. Otro párrafo esencial:

"La realidad es el desafío primero con que comienza todo pensamiento en tanto "reflexión sobre". Desde esta perspectiva es lógico que nos distanciemos radicalmente y nos encontremos, incluso, en conflicto con aquellas concepciones de la filosofía que como la hegeliana o la heideggeriana, parecen partir de la creencia de que la filosofía es un pensar que crea su propia dinámica o regularidad, su propia necesidad; que por ello mismo, puede dictar desde su "esencia" lo que es filosófico o no, o dictaminar desde sí misma su modo de habérselas con la realidad. Por esta vía se llega a la autonomía absoluta del pensar filosófico. Pero nosotros no creemos en la soberanía de la filosofía, sino más bien en una filosofía que se hace tal a fuerza de intentar contribuir a la solución de los problemas reales de sociedades históricas concretas."(p. 75)

Está claro por lo apuntado que la crítica de Fornet Betancourt se dirige en primer lugar contra los que podríamos calificar de "filósofos de salón" o "de despacho", pero quizá resulte chocante que Hegel y Heidegger comparezcan en estas líneas para denunciar filosofías de corte idealista; con el primero no hay duda, pero Heidegger no parece que esté en la lista. Pero esto no debe sorprendernos. Fornet no lo cita pero en el fondo aparece la inmensa figura filosófica de un gran desconocido, Franz Rosenzweig, quien afirmaba que toda la filosofía occidental no había salido del idealismo, de ahí que en su obra más conocida se dedique a probarlo ${ }^{7}$. Y como muy bien ha visto uno de sus grandes estudiosos, Reyes Mate ${ }^{8}$, la crítica del idealismo hecha por el filósofo judío "tiene dos vertientes: a) una más teórica y afecta a la relación entre el ser y el pensar; y b) otra más práctica y se refiere a la significación de Europa como lugar de realización del logos".

Llegados a este punto ya podemos entender que la filosofía latinoamericana será una filosofía de liberación, de emancipación, que tendrá que proceder críticamente, es decir, destructivamente, como nos lo recordaba Salazar Bondy ${ }^{9}$. Así pues y en palabras de Fornet, "desde esa experiencia se sistematiza sin duda la actual filosofía de la liberación como filosofía latinoa- 
mericana y concibe la "política" como su manera de hacer prima philosophia"(p.47). Pero esto qué significa, porque la política no puede ser por lo hasta aquí expuesto, un puro medio. Leamos a Fornet.

"Designa más bien la "política" en la perspectiva filosófico-liberacionista, la acción práctico-reflexiva del remontarse al comienzo, al origen de la experiencia de la marginación del pobre en el sistema socio-económico vigente, para acusar desde ese margen la injusticia cometida $\mathrm{o}$, si se prefiere, para hacer valer el reclamo de la justicia debida al pobre." (p. 48)

Y aquí sí cita a Levinas más adelante.

Si recordamos ahora los títulos de las obras que se van a exponer y las reflexiones de Fornet, se entenderá mejor este rodeo. En primer lugar, tanto Fornet Betancourt como Salazar Bondy coinciden en la alineación en medio de la cual ha permanecido Latinoamérica, sujeta a una realidad troquelada por un pen-

/ En conclusión, la postmodernidad - escéptica o epicúrea - es comprensible cabalmente tan sólo como un "ethos", esto es, como una actitud de indignación moral ante los excesos y desastres provocados por el programa de la modernidad; la indignación se traduce en denuncia radical; y la samiento ajeno, y esto no es otra cosa que falta de experiencia, peor aún, desperdicio de experiencia (entendida ésta en términos benjaminianos, por supuesto). Y en segundo lugar, ambos autores proponen una salida política —la prima philosophia de la que hablaba el filósofo cubano-, pero todo esto requiere una nueva cultura política, justo la segunda obra a comentar del profesor Santos.

Pero aún falta algo más. Si reparamos en algunas categorías y conceptos nos daremos cuenta que la salida no se hará desde lo Mismo, sino desde lo Otro, y esto Otro significa desde una filosofía de corte postmoderno y subversiva, no cómoda ni conformista. Así, el profesor Santos afirma que en las categorías de la Modernidad podemos encontrar todo menos la salida. $Y$ dado que nos las tenemos que haber con el pensamiento postmoderno, le dedicaremos el siguiente epígrafe como anticipo.

Comenzaremos con unas palabras de José Rubio Carracedo.

\section{Postmodernidad}

denuncia, en condena global y definitiva. Pero difícilmente podrá subsistir como postura intelectual, esto es, como pensamiento crítico ya que carece de consecuencialidad: sólo será legítimo arrojar el agua sucia - sucísima - del baño, nunca al bebé. $\mathrm{O}$, más exactamente, su crítica persistirá, pese a sus 
frecuentes exageraciones, porque es básicamente certera; pero su consecuencialidad es la rectificación y el replanteamiento del proyecto ilustrado, nunca su rechazo global, dado que su misma crítica se realiza desde dentro y con las herramientas facilitadas por el programa moderno. Este predominio del talante moral en la crítica es probablemente el responsable de la ambigüedad o estrechez de las alternativas que apenas delinean. En este sentido, sobre todo en su tendencia escéptica son más rebeldes que revolucionarios; de ahí la vaguedad de sus propuestas concretas de cambio. Por ello su legado final será asumido - está siendo asumido - por la postmodernidad "afirmativa", la nueva síntesis que marca la nueva etapa: la (post) modernidad crítica" ${ }^{10}$

¿Son certeras estas palabras de José Rubio Carracedo? ¿Sólo hay una forma de comprender el pensamiento postmoderno? ¿Hubo sólo una forma de entender la modernidad? ¿Es el paradigma de Descartes el mismo que el de Leibniz?

Dos autores van a introducirnos en el mundo post-moderno: Amalia Quevedo ${ }^{11}$ y Diego Bermejo ${ }^{12}$. Éste último expone la obra de W. Welsch.

Comencemos con Amalia Quevedo $^{13}$ y comentemos algunas de las características más notables de la postmodernidad. De todas las que menciona nos quedaremos con las más significativas para este trabajo, pues son las que presenta Santos.
(1) Rechazo de la llustración y de los conceptos ilustrados ${ }^{14}$. Por lo hasta ahora visto la Ilustración no fue sino un proyecto que enmascaraba un etnocentrismo disfrazado de universalismo. No obstante, no todos los filósofos posmodernos la rechazan de igual manera como tendremos ocasión de ver en el caso de Welsch.

(2) No identidad ni unidad, sino diferencias. Las diferencias ya no se van a integrar en el todo. No va ser la diferencia específica de Aristóteles que fertiliza un género: la diferencia simplemente difiere. Esto supone que ninguna cultura fagocita a otra. Multiculturalidad. Ello anticipa algo que Santos afirmará:

"La idea moderna de una racionalidad global de la vida social y personal acaba por desintegrarse en una multitud de mini-racionalidades al servicio de una racionalidad global incontrolable e inexplicable. Es posible reinventar las mini-racionalidades de forma que dejen de ser partes de una totalidad para convertirse más bien en totalidades presentes en muchas partes. Esta es la tarea de la teoría crítica postmoderna."15

(3) Multiplicidad, diferencia, alteridad, repetición. Deleuze hablará de multiplicidades, tratando de huir de lo Uno y lo múltiple. Todo esto asegura que ningún orden se erija como definitivo o supremo.

(4) Nuevos tipos de información y conocimiento. La verdad no está exclusivamente en la ciencia. Como veremos en Welsch, la dimensión estética será fundamental. 
(5) Fragmentación cultural. No hay una cultura hegemónica.

(6) Nuevos modos de experiencia, de subjetividad, de cultura. Construir nuevas identidades. No es el cogito cartesiano el que nos define.

(7) Modificación de la experiencia del espacio y del tiempo. Categoría central en Santos cuando tenemos que relacionarnos con otras culturas.

(8) Crítica de la representación. Contra el idealismo y sus distintas formas. La teoría no refleja especularmente la realidad ${ }^{16}$. Esto resulta también central en Santos, como se verá cuando hagamos referencia a los mapas.

(9) Perspectivismo. No hay visiones más allá del espacio y del tiempo. Este punto es especialmente antihegeliano.

(10) Política: crítica de los discursos y a las formas institucionalizadas de poder ${ }^{17}$. Este punto lo desarrolla Santos en su crítica al derecho estatal.

(11) Microteorías, micropolíticas. El fin de los metarrelatos, que diría Lyotard.

(12) Niega la coherencia social de la modernidad ${ }^{18}$. Este aspecto lo desarrolla Santos en su crítica tanto a la ciencia como al derecho modernos.

(13) Niega la causalidad a favor de la multiplicidad, la pluralidad, la fragmentación y la indetermina- ción. Los trabajos de Prygogine no pasan inadvertidos para Santos como veremos.

(14) Abandona el sujeto racional y unificado de la modernidad ${ }^{19}$ a favor de un sujeto fragmentado, social y lingüísticamente descentrado. Esto está bien perfilado en Santos.

"Es necesaria una nueva teoría de la subjetividad que explique el hecho de que nos encontramos en una compleja red de subjetividades que va incrementándose. Más allá de las ruinas del colectivismo social, está emergiendo el colectivismo del yo. La lucha frente a los monopolios de interpretación debe orientarse de tal forma que lleve a la proliferación de comunidades interpretativas políticas y jurídicas. El control disperso de la esfera jurídica contribuirá a descanonizar y a trivializar el derecho. El fin del fetichismo legalista marcará la aparición de un minimalismo jurídico y de prácticas microrevolucionarias." 20

Pasemos ahora a Welsch para completar el cuadro y por supuesto, matizarlo.

Para empezar, Welsch ${ }^{21}$ distingue tres tipos de posmodernismo.

Habría en primer lugar un posmodernismo difuso y sería el pseudo posmodernismo del "todo vale", del indiferentismo, del esteticismo anestético. Creyendo afirmar la pluralidad la disuelve en nuevas formas de uniformismo. Si todo vale, nada vale. Las críticas van dirigidas a este 
tipo porque entiende el pluralismo como "licencia de disolución" y no como "imperativo de reflexión".

Un segundo sería el que denomina integrativo u holístico. Reconoce la pluralidad pero aún siente la nostalgia unitarista, de ahí que postule alguna unidad última.

El tercero es el que nuestro autor reconoce como auténtico, preciso y normativo: el posmodernismo pluralista. Toma en serio y defiende la diferencia, el disenso, lo reprimido y lo marginal. Este posmodernismo es el intelectualmente sólido, reflexivo y crítico.

Pero ¿dónde encuentra Welsch la pluralidad? En los paradigmas, es decir, la estructura racional de concepciones diferentes. Pero he aquí una magnífica apreciación: las diferencias, siendo radicales, no son nunca absolutas.

"Convendría distinguir entre pluralidad radical y pluralidad absoluta. Por pluralidad absoluta entendemos la pluralidad concebida exclusivamente desde la heterogeneidad absoluta, de modo mosaístico y atomista, sin transitividad ni conectividad posibles entre los diversos ámbitos de la racionalidad o géneros de discurso - como es pensada por Lyotard, a través de la interpretación extrema del archipiélago kantiano y de los juegos de lenguaje wittgensteinianos. Esta concepción de la pluralidad, basada en la separación absoluta y en la negación de todo momento de unidad, resulta externa y ficticia. (...)
Por pluralidad radical entendemos la pluralidad concebida desde la heterogeneidad y desde la conectividad." 22

Estos son autónomos y heterogéneos, no hay integracionismo, no hay fagocitación. Son también inconmensurables e irreductibles, no hay un paradigma neutral. Los paradigmas definen y generan racionalidad. No son reductibles pero tampoco incompatibles, hay entre ellos imbricaciones y parecidos de familia. Es la complejidad la que nos obliga a cambiar nuestra idea de razón, no para caer en lo irracional, como se ha visto, sino para poder reflexionar de otra manera.

Decía Fornet Betancourt que la razón era racional de diversas maneras y añadíamos que ya en Kant, filósofo ilustrado, esto se mostraba ya en su obra, pero aparecían en una estricta separación. Por eso quiere Welsch mostrar que la razón cognitiva, la moral y la estética se imbrican, y son estas imbricaciones las que impiden una determinación monotética de los tipos de racionalidad.

"En adelante no se podrá saber con seguridad qué es un discurso cognitivo, un discurso estético o un discurso moral - en cualquier caso no lo que sea o debería propiamente ser. A la orden del día pertenecerán opciones en conflicto. Ya no serán posibles determinaciones generales del discurso estético, moral o cognitivo. Quizá ni siquiera podrá decirse con absoluta seguridad en 
discursos aislados y particulares si se trata de un discurso cognitivo o uno moral o uno estético." ${ }^{23}$

Pero volvamos a la razón. Unidad, pluralidad y totalidad siguen siendo referencias centrales y obligadas en la tematización de la razón, pero dada la complejidad y pluralidad en la que nos movemos, ni la unidad es síntesis última ni la pluralidad como fragmentación absoluta ni la totalidad como ordenamiento cerrado y armónico. ¿Qué concepto de razón nos permitirá abordar dichos aspectos y en estas condiciones? Deberá ser una razón transitiva, transeúnte, transida de racionalidad compleja, será, al fin, transversal ${ }^{24}$. He aquí el concepto de razón que vertebra el pensamiento de Welsch.

¿Es posible llegar a soluciones definitivas, a síntesis últimas con esta razón dada la complejidad en que se mueve?

"Es un error pensar que la razón ha fracasado cuando ya no consigue realizar ninguna síntesis última. Quien así piensa permanece completamente en las vías de la racionalidad $^{25}$, mide la racionalidad con el rasero de aquélla. El reto y la pretensión de la razón están a más altura. La razón se expone incluso a lo que no se puede entender racionalmente ${ }^{26}$. Precisamente la razón es también una facultad de transgresión de las relaciones establecidas. " 27

Caractericemos un poco más esta razón transversal. Según Welsch, dicha razón será, en primer lugar, formal, sin más contenido material propio que el de las racionalidades y paradigmas. $Y$ en segundo lugar, se presenta como competencia puramente relacional entre las racionalidades y paradigmas ${ }^{28}$.

Otra característica de esta razón es su debilidad. Va a ser, pues, una razón débil. Y es que, si se ha seguido el desarrollo anterior, "versiones "fuertes" de estilo tradicional se desechan, no sólo porque ya no están a disposición, sino porque en esta nueva situación no serían eficientes, sino más bien contraproducentes; por configuración, no estarían en situación de hacer justicia a una diversidad decisiva de formas de racionalidad. (...) Y en su debilidad radica su fuerza" 29 .

Conviene no perder de vista esta idea de debilidad pues es generalmente malinterpretada. Tras la división establecida por Welsch entre las formas de posmodernismo, debe quedar ya claro que se trata de una razón comprometida y eminentemente crítica, alejada de cualquier conformismo o confort. No es una razón cobarde ni derrotada, no es una razón cansada, aburrida o extenuada, cómplice al fin con el orden establecido. Es una razón que reconoce la complejidad de la realidad y sabe que nunca se va a instalar en ella ni cómoda ni definitivamente. Es justamente lo contrario del idealismo, y como ya hemos visto, comenzando por Fornet Betancourt, una filosofía emancipadora se hace cargo de la realidad, no la troquela 
definitivamente con conceptos cerrados, la realidad no se resuelve en la conciencia.

¿Cuál será la meta de esta razón transversal? No será la verdad sino la justicia, ésta es una idea específica de la razón. Y ello por tres hechos: primero por la competencia de la totalidad ${ }^{30}$ de la razón. En segundo lugar por la concurrencia de una multiplicidad de formas de racionalidad y de paradigmas con diferentes versiones de la totalidad. Y por último, por la irreductibilidad y legitimidad de los diferentes complejos racionales.

"La justicia racional representa la perspectiva motriz de una razón que, siguiendo su compromiso con la totalidad, choca con la circunstancia de que el todo ya no se somete a un orden unitario, sino que permanece caracterizado por una multiplicidad de racionalidades y opciones encontradas. A esta situación puede corresponder sólo el ideal de justicia." ${ }^{31}$

La razón transversal se revela también como razón práctica porque la situación actual ha impuesto un giro pragmático y antiteoricista en la tematización de la razón. Y es que los ideales clásicos de la razón son un obstáculo para dar cuenta de una razón y una realidad inmersas en la contingencia, finitud, diversidad, complejidad, mutabilidad e inabarcabilidad. Así pues la razón transversal incorpora el giro pragmático y se presenta como fundada en la praxis y dirigida a la praxis.
Todo esto nos permite recuperar una idea tan clásica como la de "sabiduría", "entendida en sentido práctico —más amplio que el concepto de saber teorético -que incluye las connotaciones de experiencia, relativización, discernimiento en la contingencia, flexibilidad, conciencia de limitación, sentido de la globalidad, adaptabilidad, etc.." ${ }^{\prime \prime 2}$

Esta concepción de la sabiduría la encontraremos en la obra de Santos: una ciencia prudente para una vida decente.

Otro aspecto destacable de la razón transversal es su constitución intrínsecamente estética. La razón transversal es una razón de matices, atenta a la particularidad, a la diferencia y al detalle; razón abierta a la percepción de latencias, exclusiones, márgenes; razón creadora, flexible, etc. ${ }^{33}$

$\mathrm{Y}$ ya para concluir nos detendremos en uno de los puntos más importantes, el de la subjetividad. Veremos que coincide en parte con lo expuesto anteriormente por Amalia Quevedo, pero resultan de gran relevancia los matices. Veámoslo.

Ser sujeto hoy significa ser capaz de actuar en medio de una realidad plural, y para ello es preciso perder la idea de identidad como centro, lo que no quiere decir que el sujeto se disuelva, simplemente se transforma. Pero una vez más habrá que añadir que este sujeto no es camaleónico ni mimético, sino capaz de distanciamiento, elección y modificación. Es un sujeto que 
reinterpreta su identidad de forma narrativa. Y otra característica de este sujeto será su debilidad — "en la debilidad está la fuerza", según Welsch - idea que ahora debiera estar más clara tras lo señalado con anterioridad. ${ }^{34}$

Una vez finalizado el recorrido por el postmodernismo y vistas algunas de sus aportaciones más importantes es el momento de adentrarnos en el original y fértil pensamiento de un autor realmente innovador. Y lo haremos analizando esa batería de categorías que el autor expone con brillantez en "Crítica de la razón indolente. Contra el desperdicio de la experiencia".

\section{3. ¿Por qué es tan difícil construir una teoría crítica?}

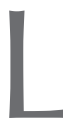

a obra de Santos, influenciada por la de Immanuel Wallerstein, se ubica en lo que podemos llamar transición paradigmática $^{35}$. Los paradigmas nacen, se desarrollan y mueren; el nuevo, por su lado, es inconmensurable con el anterior, de ahí que dicha transición sea semiciega y semiinvisible. El paradigma capitalismo-modernidad entró en un proceso de degradación cuyo fin parece encontrarse en el umbral del tercer milenio. Por decirlo con palabras del propio Santos:

"El paradigma sociocultural de la modernidad aparecerá antes de que el modo de producción capitalista llegue a ser dominante y desaparecerá antes de que éste último cese. Esta desaparición es compleja porque es en parte un proceso de abandono, y en parte un proceso de obsolescencia. Es abandono en la medida que la modernidad ha cumplido alguna de sus promesas, en algunos casos incluso en exceso. Supone un proceso de obsolescencia en cuanto que la modernidad ya no es capaz de cumplir otras. Tanto el exceso como el déficit de realización de las promesas históricas explica nuestra difícil situación actual que aparece en la superficie como un período de crisis, pero que en un nivel más profundo, constituye un período de transición. Desde el momento que todas las transiciones son parcialmente visibles y parcialmente ciegas, resulta imposible calificar nuestra situación actual. Probablemente esto explique por qué la inadecuada denominación "postmoderna" haya llegado a ser tan popular. Mas por la misma razón, este calificativo es auténtico en su inadecuación." ${ }^{\prime \prime 6}$

La transición paradigmática para Santos presenta dos dimensiones:

a) Epistemológica: entre el dominante de la ciencia moderna y el emergente, un conocimiento prudente para una vida decente ${ }^{37}$.

b) Social: entre el dominante - patriarcalismo, consumismo, etc. - y el emergente, del que aún no percibimos sino las "vibraciones ascendentes". 
El primer paso a dar será presentar una crítica del paradigma dominante, pero que se aleja de las teorías críticas de la modernidad en tres aspectos fundamentales que marcan y perfilan el desarrollo posterior de toda la obra.

1.- Mientras la teoría crítica moderna es subparadigmática —esto es, procura desarrollar las posibilidades emancipadoras dentro del paradigma dominante - la de Santos es paradigmática, no es posible lo anterior. ${ }^{38}$

2.- Si la teoría crítica moderna presenta su trabajo como "desfamiliarización", la nueva teoría entiende ésta como un momento de suspensión necesaria para crear una nueva familiaridad, no como ruptura.

3.- El tercer aspecto reside en la autorreflexividad de la nueva teoría, es decir, en la permanente autocrítica y de ahí la autocorreción correspondiente.

Otro aspecto original, muy benjaminiano, es la idea de excavación. Se trata de recuperar en medio de las ruinas producidas por la modernidad residuos culturales, sociales y políticos que ayuden a reinventar la emancipación social pues ésta tiene sus raíces en lo excluido por el progreso, otro concepto moderno. ${ }^{39}$

Pero volvamos a la pregunta. ¿Por qué es tan difícil construir una teoría crítica? Una primera respuesta es porque nos hallamos en una realidad —en el sentido zubiriano del término, es decir, en un campo de posibilidades - muy compleja. Y de ahí la dificultad apuntada anteriormente. Este aspecto es crucial en la obra de Santos porque es coherente con las premisas en que se asienta su teoría crítica y ya apunta algo de gran interés: no hay soluciones definitivas porque la realidad es inagotable, siempre da de sí. Pero hay más respuestas y son éstas según Santos:

La teoría crítica moderna concibe la sociedad como una totalidad $y$, como tal propone una alternativa total a la sociedad existente. La nueva teoría crítica entiende que no hay un único principio de transformación social, tampoco hay agentes históricos únicos ni una forma única de poder. ${ }^{40}$

En segundo lugar, para Santos, la industrialización no es necesariamente ni el motor ni la partera del desarrollo. Hoy el problema no es la creación de riqueza sino su distribución.

Así pues nos enfrentamos con problemas modernos cuyas soluciones, como antes se apuntaba, no las encontraremos en el proyecto de la modernidad, hace falta una teoría alternativa, una teoría crítica post - moderna inquietante o de oposición. ${ }^{41}$ Por tanto necesitamos un pensamiento alternativo de alternativas.

\section{I. Hacia una teoría crítica post- moderna $^{42}$}

Para una teoría crítica postmoderna, todo el conocimiento crítico 
tiene que comenzar por la crítica del propio conocimiento, y se propone como punto de partida el binomio conocimiento-emancipación, marginado por la modernidad. En esta forma de conocimiento la ignorancia es colonialismo, ver en el otro un objeto, y el conocimiento es justamente reconocimiento, solidaridad.

La opción por el binomio conocimiento-solidaridad presenta tres implicaciones:

1.- Del monoculturalismo al multiculturalismo. Éste último choca con dos dificultades:

a.- El silencio. Silencio producido por la destrucción de muchas formas de saber — de ahí la excavación, las ruinas-, en su mayor parte, coloniales.

b.- Diferencia. Sólo puede haber conocimiento en la solidaridad en las diferencias. Además esta solidaridad sólo se dará en lo que Santos Ilama "traducción" vía hermenéutica diatópico, que permita que una aspiración o práctica en una cultura pueda ser inteligible para otra ${ }^{43}$.

2.- El segundo desafío es el siguiente: de la pericia heróica al conocimiento edificante. La ciencia moderna no fue autorreflexiva, jamás pensó en las condiciones que la posibilitaban, así desarrolló una gran capacidad de acción pero no de previsión. Este desequilibrio produjo el heroísmo técnico y el tipo de profesional que hoy domina. El conocimiento edificante se basa en maximizar la objetividad y minimizar la neutralidad, en una ciencia con conciencia.

3.- El tercer desafío puede formularse así: de la acción conformista a la rebelde. No hay oposición entre estructura y acción. Para Santos, las estructuras son tan dinámicas como las acciones, de ahí este desafío. Otro punto de apoyo es que tanto determinación como indeterminación ya no son conceptos sino variables empíricas, así las acciones y subjetividades son tanto producto como productoras de procesos sociales. No obstante, la construcción social de rebeldía se encuentra con algunos obstáculos:

a.- El primer desafío consiste en la discrepancia entre experiencias y expectativas ${ }^{44}$. Al exceso de expectativas sobre las experiencias le llamamos progreso y éste es el gran error, pues de experiencias mediocres no pueden concluirse sino expectativas del mismo cuño. ${ }^{45}$

b.- El segundo apunta a la dicotomía consenso-resignación. Ya, según Santos, ni las clases hegemónicas buscan el consenso pues tal es la confianza en la falta de alternativas a la situación actual, y esto, en una población alienada, genera resignación.

c.- La dicotomía espera-esperanza sería el tercer desafío. Al igual que en el primer caso, vivimos una espera sin esperanza y para poner fin a esta situación, recu- 
perar la esperanza, sería imprescindible alterar la espera tornándola más activa y ambigua.

Como habrá podido observarse, la teoría crítica postmoderna de Santos, rescata en primer lugar conceptos olvidados por la modernidad para profundizar más en esa realidad que, como dijera Zubiri, "de suyo da más de sí". Así pues esta teoría debe hacerse cargo de la diversidad y de la complejidad de una sociedad que, como se afirmaba, no se puede simplificar buscando agentes sociales únicos o formas de dominio únicas. Si se quiere resolver un problema, la condición necesaria es plantearlo bien definiendo todas sus variables relevantes y estudiando sus relaciones. Más adelante, el propio Santos nos dirá que su teoría es fiel represen- tante de un optimismo trágico. Optimismo porque se puede y se debe actuar - "lo que es no es posible", decía Adorno-, como se decía, tras un profundo análisis de la sociedad. Trágico porque no hay soluciones definitivas, la complejidad de la realidad lo impide, de ahí la autorreflexividad y autocrítica teóricas. ¿Qué hay de la utopía?

"Lo que hace cambiar las sociedades y las épocas es el exceso de problemas que suscitan con respecto a las soluciones que hacen posibles. La teoría crítica reside en la conciencia de ese exceso. Su aspiración utópica no reside en proponer soluciones desproporcionadas a los problemas planteados, sino en la capacidad de plantear problemas nuevos para los cuales no existen, o no existen aún, soluciones." ${ }^{46}$

\section{Un nuevo sentido común}

Qué ocurre cuando los espejos se convierten en estatuas?

"Cuando esto ocurre, la sociedad entra en una crisis que podemos denominar como crisis de la conciencia especular: de un lado, la mirada de la sociedad se une al terror de no ver reflejada ninguna imagen que reconozca como suya; de otro, la mirada monumental, fija y opaca del espejo vuelto estatua parece atraer la mirada de la sociedad, no para que ésta vea, sino para que sea vigilada." ${ }^{\prime 7}$
¿Qué ocurre cuando las instituciones lejos de facilitarnos la convivencia se convienen en corsés que nos oprimen? He aquí una de las causas de nuestro actual malestar.

"Entre los muchos espejos de las sociedades modernas, hay dos que, por la importancia adquirida, parecen haber pasado de espejos a estatuas: la ciencia y el derecho. El proceso histórico en el que esto ocurrió fue el resultado de la combinación de dos procesos históricos distintos: el paradigma de la mo- 
dernidad occidental y el capitalismo." ${ }^{\prime 48}$

No es una casualidad que Santos, como estudioso del derecho, lo haya expresamente elegido para elaborar una teoría crítica. Si la ciencia es el único saber riguroso, el derecho, influenciado por ésta y como gran institución, deberá racionalizar el Estado y la sociedad, es decir, será generador del orden social.

\section{De la ciencia moderna al nuevo sentido común}

El modelo de racionalidad que preside la ciencia moderna se desarrolló en las ciencias naturales para después colonizar ya en el siglo XIX las ciencias sociales. A partir de aquí se puede hablar de un modelo global de racionalidad científica que rechaza dos formas de conocimiento no científico: el sentido común y las Ilamadas humanidades. Así este modelo niega todas las formas de conocimiento que no se adecuen a sus principios epistemológicos o a sus reglas metodológicas. Como antes se denunciaba, se trata de un modelo totalitario. ${ }^{49}$

Por otro lado, dicho modelo conduce a dos distinciones fundamentales, primero: conocimiento científico y conocimiento de sentido común; segundo: naturaleza y persona, que bien puede suplir la cartesiana mente y cuerpo.

La primera distinción pone de manifiesto el descrédito que para el conocimiento científico ofrecen los sentidos: éstos simplemente nos proporcionarían un conocimiento vulgar. La segunda va a ser fatal y estará en el fondo de la crisis que hoy vivimos.

"Por otro lado, la separación entre naturaleza y ser humano es total. La naturaleza es tan sólo extensión y movimiento; es pasiva, eterna y reversible, es un mecanismo cuyos elementos se pueden desmontar y después relacionar bajo la forma de leyes; no tiene ninguna otra cualidad o dignidad que nos impida desvelar sus misterios, desvelamiento que no es mera contemplación, sino algo activo, ya que tiende a conocer la naturaleza para dominarla y controlarla. Como dijo Bacon, la ciencia hará del ser humano el señor y el poseedor de la naturaleza." ${ }^{50}$

Es innegable el espíritu cartesiano en lo que hasta aquí vamos estudiando. Pero no se puede olvidar que el paradigma moderno que nace con Descartes está basado en una filosofía de corte idealista ${ }^{51}$ que va de las ideas a las cosas y no al revés, y esto tiene sus consecuencias.

Ideas claras y sencillas, esto es lo que necesitamos si queremos llegar al fondo de las cosas, pero esto sólo podemos lograrlo en las matemáticas. ¿Es universalizable el método matemático? Esta pregunta es crucial en la teoría de Santos porque como veremos más adelante en la "epistemología de la ceguera", ésta justamente apunta al empobrecimiento y a la falsificación de la realidad. 
En el método matemático, saber es cuantificar, y el rigor se mide por la precisión de las mediciones. ¿Qué ocurre con las variables cualitativas? Simplemente son irrelevantes ${ }^{52}$. Pero al no ser tenidas en cuenta, lo que queremos conocer no sólo se ha empobrecido sino que se ha falsificado, pues la realidad, que era justamente lo que queríamos conocer, ha perdido complejidad. Al ir de las ideas a las cosas, al imponer un método muy restrictivo, las cosas han desaparecido para dejar su lugar a las ideas.

Este tipo de conocimiento, y ahora ya se puede comprender, que tiene como fin descubrir legalidades, presupone una idea de orden y de estabilidad, presupone la idea de que todo el pasado se repetirá en el futuro. Es pues un mundo-máquina.

"Esta idea de mundo máquina es tan poderosa que va a transformarse en la gran hipótesis universal de la época moderna. Puede parecer sorprendente, y hasta paradóji$\mathrm{CO}$, que una forma de conocimiento sustentada en tal visión del mundo se haya constituido en uno de los pilares de la idea de progreso que gana cuerpo en el pensamiento europeo a partir del siglo XVIII y que se presenta como la seña intelectual del ascenso de la burguesía. Pero la verdad es que el orden y la estabilidad del mundo son la precondición de la transformación tecnológica de lo real."

Como ya se advertía, lo que subyace es una idea de conocimiento utilitario y funcional que lejos de comprender lo real se limita a dominarlo y transformarlo: si hemos descubierto las leyes de la naturaleza, descubriremos también las leyes de la sociedad. ${ }^{53}$

Nada de esto debe extrañarnos pues el ambiente intelectual está poseído por el positivismo en su tercera fase según afirmaba Compte. ${ }^{54}$

Pero esto, siendo cierto, no es todo, porque como bien señala Santos, hay otra corriente intelectual que considera a las ciencias sociales en un plano distinto y reivindica para ellas otro estatuto epistemológico. La especificidad del ser humano no es reductible a leyes físico-matemáticas, además la acción humana es radicalmente subjetiva. De acuerdo, pero ¿tanto difieren ambas corrientes? Para Santos, no. Veámoslo.

La segunda concepción comparte con la primera más de lo que a primera vista parece. Para empezar comparte la distinción naturaleza-ser humano, teniendo para aquella una visión también mecanicista. A esta distinción se añaden dos más: naturaleza-cultura; y ser humano-animal.

"La frontera que se establece entonces entre el estudio del ser humano y el estudio de la naturaleza no deja de ser prisionera del reconocimiento de la prioridad cognitiva de las ciencias naturales, pues si por un lado, se recusan los condicionantes biológicos del comportamiento del ser humano, por el otro se usan argumentos biológicos para fijar la especificidad del ser humano." ${ }^{55}$ 
¿Qué aporta esta segunda corriente? Para Santos, más que aportar, muestra una señal de crisis paradigmática profunda e irreversible; los posteriores desarrollos de la ciencia —la mecánica cuántica, el teorema de incompletud, la teoría de Prigogine, etc. - la confirmarán. En resumen, estamos en plena transición paradigmática.

\section{El paradigma emergente}

Ya sabemos algo de él: es el paradigma del conocimiento prudente para una vida decente. Combina pues un paradigma científico y uno social. Si queremos analizarlo correctamente no podemos caer en un pesimismo reaccionario ni en un voluntarismo irresponsable e inconsecuente. "Solo a partir de la modernidad es posible transcender la modernidad". ¿Cómo ir perfilándolo? Para ello nos preguntaremos cuáles son las representaciones inacabadas de la modernidad, por ahí comenzaremos a atisbarlo. Sigamos con detenimiento a Santos.

El paradigma de la modernidad se asienta en dos pilares:

- Regulación

- Emancipación

A su vez, el principio regulación se apoya en tres lógicas:

a1) El principio del Estado. Tiene como representante a Hobbes y consiste en la obligación política vertical entre ciudadanos y Estado. a2) El principio del mercado. J. Locke y A. Smith lo representarían, y se basa en la obligación política horizontal individualista y antagónica entre los que participan en él.

a3) El principio de la comunidad. Aquí hallaríamos a J.J. Rousseau como representante. Consiste en la obligación horizontal y solidaria entre los miembros de la comunidad y asociaciones.

El pilar de la emancipación está constituido por las tres lógicas de M. Weber:

b1) La racionalidad estético expresiva de las artes y de la literatura

b2) La racionalidad cognitivoinstrumental de la ciencia y de la tecnología

b3) La racionalidad moralpráctica de la ética y del derecho.

Este paradigma pretendía un desarrollo armonioso y recíproco entre ambos pilares así que generase una racionalización de la vida individual y colectiva. Ya hemos visto que esto nunca se cumplió, así que volvamos a la pregunta anterior: ¿cuáles son las representaciones inacabadas $y$, por tanto, más abiertas de la modernidad? ¿cuáles son los pilares menos dañados?

En el campo de la regulación, el principio de la comunidad; en el de la emancipación, la racionalidad estético expresiva. Santos comienza por una detección minuciosa de estos principios, pues son los mejor 
colocados para instaurar una dialéctica positiva en ellos.

El principio comunidad presenta dos dimensiones:

Participación. Se colonizó en parte en el contexto de la esfera política (ciudadanía y democracia representativa), pero dejó abiertos otros espacios.

Solidaridad. También se colonizó de forma incompleta por las intervenciones del Estado providencia aunque permaneció un tipo de solidaridad comunitaria no especializada.

En relación al pilar de la emancipación fue la racionalidad estético expresiva la menos colonizada, pues como la obra de arte, siempre permanece inacabada y por ello nunca puede ser encerrada. $Y$ esta permanente apertura de la racionalidad estético expresiva, reside en los conceptos de:

a) Placer. Para Santos el placer sufrió una cierta colonización a través de la industrialización del ocio y de los tiempos libres Ilevada a cabo por las industrias culturales. Con todo, para nuestro autor, aún permanece un reducto, el "homo ludens", que resiste al enclaustramiento y difunde el juego, el que como decía Unamuno, se juega por jugar, sin más finalidad.

b) Autoría. Es justo lo contrario de la "auctoritas" y frente a ésta se desarrolla en el dominio artístico y literario, sobre todo en el Renacimiento. El autor es entendido como aquél que se opone a lo vulgar, como creador autónomo que inventa nuevos mundos culturales. Santos considera inaceptable hablar de la muerte del autor pues ninguno puede ser causa sin antes haber sido efecto. Esto va contra las corrientes estructuralistas y post-estructuralistas para las que el autor no sería sino un efecto de las estructuras sociales, pero ya hemos visto que ya no hay separación absoluta entre estructuras y accioes.

c) Artefactualidad discursiva. Todas las obras de arte tienen que ser creadas o construidas, es decir son la culminación de un proceso intencional, son por eso artefactos discursivos. Santos se sirve de este concepto para reivindicar un conocimiento post-moderno frente a la ciencia moderna que naturaliza el conocimiento a través de verdades objetivas, descripciones y regularidades.

Nietzsche decía que debíamos hacer de nuestra vida una obra de arte y esto parece estar también en la mente de Santos. Esa vida decente pasa porque vivamos la vida reivindicando la experiencia, esto es con sabiduría, una sabiduría que va implícita en ese nuevo sentido común al que después se hará referencia.

Hechas estas reflexiones, demos un paso más en el estudio.

\section{Del conocimiento regulación al conocimiento emancipación}

Para empezar, Santos niega algo así como un saber en general o una 
ignorancia en general, todo saber es de una cierta ignorancia, y toda ignorancia es de un cierto saber. El conocimiento sería un trayecto que va de la ignorancia al saber.

El conocimiento emancipación iría desde un estado "colonialismo" (ignorancia) $)^{56}$ a otro: el de "solidaridad" (saber). Por su parte, el saber regulación iría del "caos" (ignorancia) al "orden". Para la modernidad los dos pilares se articulaban en equilibrio dinámico y, así, el orden potenciaba la solidaridad y viceversa. Y, como ya se ha visto, eran las tres lógicas weberianas las encargadas de mantenerlo. Pero como también se ha podido ver, la colonización del mundo de la vida por la razón científico técnica arruinó el proceso. ¿Cuál es nuestra situación actual?

Si el conocimiento regulación se impone al conocimiento emancipación, la conclusión es inmediata: el orden se transforma en la forma hegemónica del saber y el caos como la forma hegemónica de la ignorancia. Hay, por tanto, no sólo un desequilibrio, sino una nueva recodificación.

"Este desequilibrio a favor del conocimiento regulación permitió a éste último recodificar bajo sus propios términos al conocimiento emancipación. Por ello, el estado de saber en el conocimiento emancipación pasó al estado de ignorancia en el conocimiento regulación (la solidaridad fue recodificada como caos) e, inversamente, la ignorancia en el conocimiento emancipación pasó al estado de saber en el conocimiento regulación (el colonialismo fue recodificado como orden)." ${ }^{157}$

Si queremos salir de esta situación el conocimiento emancipación debe ser reevaluado y potenciado, y esto supondría dos cosas: la primera es que la solidaridad se transformase en forma hegemónica del saber; la segunda es que el caos, antes condenado a la ignorancia, no sólo sea aceptado sino que sea aceptado como forma de saber. Es decir, el orden coexiste con el caos, y esto no es una contradicción, antes bien, apoya la crítica que Santos hacía de la modernidad al calificarla como "totalitaria". El caos es el elemento imprescindible si queremos realmente conocer la realidad, una realidad dinámica y sistemática, diversa y compleja, que nunca se dejará aprehender con conceptos ya prefijados. Y aquí resuena también de nuevo la crítica a Descartes, "va de las ideas a las cosas".

Pero yendo más allá, encontramos en el caos justo eso que reivindicaba Santos en su nuevo paradigma: un conocimiento prudente para una vida decente. El caos no nos permite seguir pensando que conocidas las causas, conocidos los efectos, y esto debe volvernos prudentes. El principio de prudencia nos impone una doble exigencia:

"Por un lado, exige que ante los límites de nuestra capacidad de previsión, en comparación con el poder y la complejidad de la praxis 
tecnológica, privilegiemos indagar las consecuencia negativas de ésta en detrimento de las consecuencias positivas. (...) Las consecuencias negativas dudosas, pero posibles, deben ser tenidas como si fueran ciertas. (...) Es preciso construir una teoría de la personalidad asentada en el coraje de tener miedo." ${ }^{58}$

Y la segunda:

"En revalorizar la solidaridad como forma de saber. La solidaridad es una forma de saber que se conquista sobre el colonialismo. El colonialismo consiste en la ignorancia de la reciprocidad y en la incapacidad de concebir al otro sino como objeto. La solidaridad es el proceso, siempre inacabado, de volvernos más capaces de reciprocidad a través de la construcción y del reconocimiento la intersubjetividad. (...) Como la nueva subjetividad depende menos de la identidad que de la reciprocidad, puede y debe ser reconstruida al margen del antropocentrismo: la naturaleza, llamada no humana, no siéndonos idéntica, nos es recíproca en la medida en que, por ejemplo, su destrucción acarrea la nuestra. De este modo, nuestra subjetividad no se completa sin ella." ${ }^{59}$

Central será este concepto de "reciprocidad" para todo el análisis posterior pues gracias a él Santos irá deconstruyendo ${ }^{60}$ todas las dicotomías que aparecen en el paradigma moderno de la ciencia.

La primera será la sujeto-objeto, $y$ es que no hay conocimiento que no sea autoconocimiento. Esta dicotomía, al valorar uno de los polos, condena al otro a la nada, así lo veíamos paginas atrás donde la naturaleza quedaba completamente descalificada. Si esta dicotomía la reflejamos en la antropología, el sujeto, el antropólogo occidental civilizado, está a años luz del nativo, primitivo o simplemente salvaje, pues ¿Cómo calificar a un polo si el otro "encarna" la perfecta civilización?

Otra dicotomía que es prolongación de la primera, sería naturaleza-cultura. ¿es pensable la cultura sin la naturaleza?

Todo esto nos lleva a una concepción sexista de la ciencia pues siempre potencia uno de los polos en detrimento del otro, siempre hay uno dominante y otro dominado.

Si todo conocimiento es autoconocimiento, todas las ciencias son sociales. Y esta superación tiende así a revalorizar los "estudios humanísticos, pero esta revalorización no ocurrirá sin que las humanidades sean también profundamente transformadas. Su resistencia a aceptar las dicotomías expuestas y haber priorizado la comprensión frente a la manipulación es lo que les permite tener abrirse al futuro.

\section{Argumentación}

Continuando con las posiciones anteriores, Santos va a profundizar más en el conocimiento emancipación y lo define como un conocimiento local creado y diseminado a través del discurso argumentativo 
que se da dentro de comunidades interpretativas, los auditorios relevantes.

"La ciencia moderna tuvo que luchar contra un enemigo poderoso: los monopolios de interpretación, fuesen la religión, el estado, la familia o el partido. Fue una lucha trabada con enorme éxito y cuyos resultados positivos van a ser indispensables para crear un conocimiento emancipador postmoderno. El fin de los monopolios de interpretación es un bien absoluto de la humanidad." 61

Pero como ya sabemos también, al colonizar la ciencia el mundo de la vida, expulsó al resto de los saberes engendrando un nuevo enemigo tan peligroso como el anterior: la renuncia a la interpretación. Ya puede afirmarse por tanto que un conocimiento emancipador debe luchar tanto contra los monopolios de interpretación como contra la renuncia a la interpretación. ¿Cuál es la estrategia a seguir? La proliferación de comunidades interpretativas, es decir, el fomento de la multiculturalidad. ¿Qué son esas comunidades?

Para Santos son comunidades políticas. Pero este principio "comunidad" debe ser depurado porque si no, bien pudiera pensarse que lo que aquí se defiende es una especie de comunitarismo y no es así.

"Los comunitaristas tienden a concentrarse en las relaciones intracomunitarias y en la interacción solidaria, ignorando tanto las relaciones inter-comunitarias como la interacción colonialista que casi siempre las domina. La trayectoria que parte del colonialismo a la solidaridad tiene que atravesar tanto las relaciones inter-comunitarias como las intra-comunitarias. La emancipación social emerge de la tensión dialéctica entre el comunitarismo que domina las relaciones intra-comunitarias y el contractualismo que domina las relaciones inter-comunitarias." 62

Una nueva dicotomía ha sido deconstruida, la oposición se torna tensión permanente cuyo resultado nunca alcanzable da como fruto la reinvención de la comunidad.

"Reinventar la comunidad desde un conocimiento emancipador que habilite a sus miembros a resistir al colonialismo y a construir la solidaridad por el ejercicio de nuevas prácticas sociales, que conducirán a nuevas y más ricas formas de ciudadanía individual y colectiva. ${ }^{63 \prime \prime}$

¿Cómo será un conocimiento emancipación que lucha tanto contra los monopolios de interpretación como contra la renuncia a la interpretación? Será retórico pues sólo éste se aproxima a la racionalidad estético-expresiva.

"La verdad es retórica, una pausa mítica en una batalla argumentativa continua e interminable trabada entre varios discursos de verdad." ${ }^{64}$

Pero Santos va más allá y ve la centralidad de la retórica en dos vertientes: 1) la ciencia moderna, a pesar de su discurso, es retórica también; 2) en el nuevo paradigma 
emergente, el conocimiento será retórico, pero de cuño diferente. Veamos el primer punto.

Puede parecer chocante en primer lugar que se hable de retórica en el discurso científico que precisamente se presenta como anti-retórico, pero esto no debe sorpredernos pues Santos ya ha mostrado que ni en el campo científico podemos partir de fundamentos lo suficientemente sólidos como para construir teorías definitivas sobre ellos. Así pues la ciencia, como cualquier otro tipo de conocimiento, será retórica.

"La retórica es una forma de Conocimiento que avanza desde premisas probables hacia conclusiones probables mediante varios tipos de argumentos algunos de los cuales pueden revestir la forma silogística, aun no siendo específicamente silogismos. Los argumentos son de una inmensa variedad, pero sólo pueden ser aplicados a un proceso concreto si se cumplen dos condiciones: tiene que haber algunas premisas generalmente aceptadas que funcionen como punto de partida para la argumentación; y tiene que haber un auditorio relevante al que persuadir o convencer." ${ }^{65}$

Esas premisas generalmente aceptadas que funcionan como punto de partida para la argumentación no son sino lugares comunes, que pueden dejar de serlo, entonces se convierten en argumentos. Estamos lejos de esas "ideas claras y distintas" a las que aludía Descartes.
Pasemos a los auditorios. Santos distingue entre auditorios específicos, compuestos por un número mayor o menor de personas influenciables por la argumentación; el individual, una persona que delibera o pondera una decisión; y el universal, potencialmente, toda la humanidad.

¿De qué naturaleza son los "topoi" —puntos de vista ampliamente aceptados en una comunidad- de la ciencia?

Como en cualquier otro ámbito, los topoi aparecen agrupados en pares opuestos. En la ciencia aparecen el de la cantidad y el de la cualidad. Como ya sabemos, fue el de la cantidad el que prevaleció y así empujó al de la cualidad a la marginalidad, es decir, a los discursos desvalorizados. El coste de ello fue muy elevado, como sabemos, pues a partir de ese momento cualquier forma de racionalidad debía presentarse como cuantitativa.

El último punto a tratar será el del auditorio de la ciencia. Al presentarse ante un auditorio universal, la ciencia cree estar al margen de la retórica pues tan sólo utiliza la prueba lógica, pero esto no es sino una forma como otras de argumentar.

Tras este recorrido por la retórica científica, tenemos que dar un paso más, pues se decía que en el paradigma emergente el conocimiento emancipación será retórico, pero de corte diferente al anterior. Veámoslo ahora. 
La novísima retórica que presenta Santos, parte de algo que ya sabemos, que es una forma de argumentar razonablemente con el objetivo de explicar resultados ya consumados o procurar adhesión a la producción de resultados futuros. Estos argumentos pueden servirnos para persuadir o convencer. Pues bien, la novísima retórica se caracteriza por priorizar el convencimiento frente a la persuasión. No se trata de intensificar emociones sino de dar buenas razones.

"Una retórica que privilegie la obtención de convencimiento tenderá a contribuir por un lado, a un mayor equilibrio entre razones y resultados, entre contemplación y acción, y, por otro, a una mayor indeterminación de la acción, dos presupuestos de un conocimiento prudente para una vida decente en un período de transición paradigmática." ${ }^{166}$

Si la retórica anterior era monológica, con el orador en primer plano, en la nueva, orador y auditorio no representan pos iciones rígidas sino intercambiables. En esta nueva retórica, además, los topoi no son tan estables y duraderos, pero quizá lo más importante, es que los pares de topoi interactúan dialécticamente generando nuevos topoi que inventan y enriquecen nuevos campos de conocimiento compartidos.

Para esta retórica el auditorio está en permanente formación perdiendo la rigidez habitual. Presta mucha atención al nacimiento a los procesos por los cuales los auditorios nacen, crecen y se extinguen, $y$ esto es de gran importancia porque para Santos, en el sistema capitalista la realidad social no puede reducirse a la argumentación y al diálogo, y porque la retórica no es liberadora por naturaleza.

"Más allá de la argumentación y del discurso, hay también trabajo y producción, silencio y silenciamiento, violencia y destrucción. Sin tener en cuenta la dialéctica entre momentos argumentativos y no argumentativos es imposible entender la construcción y destrucción sociales de auditorios y comunidades."

\section{Una tópica de emancipación: hacia un nuevo sentido común}

Buscábamos un nuevo sentido común y parece que contamos con los elementos necesarios para ello. La ciencia siempre ha considerado el sentido común como algo superficial ilusorio y falso. Frente al conocimiento objetivo, el sentido común aparece como mera opinión o prejuicio. Para acabar con esta dicotomía, Santos apuesta por una doble ruptura epistemológica.

"Propongo la idea de una doble ruptura epistemológica como forma de superar este callejón sin salida. La expresión "doble ruptura epistemológica" significa que después de consumada la primera ruptura (permitiendo que con ello la ciencia se diferencie del sentido común), hay otro aspecto epistemológico importante que queda por realizar: 
romper con la primera ruptura con el objetivo de transformar el conocimiento científico en un nuevo sentido común." 67

Es importante repetir que el nuevo sentido común no surge en contra de la ciencia sino que convierte el conocimiento en autoconocimiento, y así el desarrollo tecnológico se traduce en sabiduría de la vida ${ }^{68}$. Además, si esta teoría crítica se basa en la complejidad, diversidad y riqueza de la realidad, no podemos afirmar que haya un solo sentido común sino varios. La importancia de este análisis se descubrirá cuando Santos estudie los seis conjuntos de relaciones sociales que constituyen las formaciones sociales capitalistas.

El nuevo sentido común es también solidario. Es un sentido común también responsable. La preocupación y el cuidado nos pone en el centro de todo cuanto ocurre ante nosotros, nos hace responsables ante los otros, sea un ser o un grupo humano, sea la naturaleza. Para este nuevo sentido común preñado de responsabilidad, tanto la naturaleza como el futuro tienen derechos sin tener deberes. Es también participativo y posee una fuerte vocación política. En resumen, es un sentido común reencantado y apasionado.

Una vez concluida la crítica del paradigma moderno de la ciencia, Santos comenzará la critica de la otra institución, ese otro espejo convertido en estatua: el derecho, la otra gran institución de la modernidad.

\section{Hacia una concepción post-moder- na del derecho}

Lo que Santos se propone en este epígrafe es mostrar que la transformación de la ciencia moderna en la racionalidad hegemónica y en la fuerza productiva fundamental, por un lado, y la transformación del derecho en derecho estatal científico, por otro, son las dos caras del mismo proceso histórico. Dichas transformaciones se produjeron paulatinamente y se registraron en la tensión regulación-emancipación.

La relación entre regulación y emancipación muestra sus primeras tensas manifestaciones en la Europa del siglo XII. La recepción del derecho romano fue un extraordinario movimiento intelectual; fue además un proceso de creación de derecho que colisionó con lo que podíamos llamar "sistema jurídico feudal", que suponía un pluralismo jurídico extremo de modo que una persona podía estar sujeta a distintos órdenes. Esto podía ser fuente de libertad pero a la vez era también fuente de caos y arbitrariedad. La convergencia de intereses económicos y culturales favoreció la recepción del derecho romano y con él apareció un saber jurídico humanista, laico y autónomo. Esta autonomía del derecho se veía como un salto revolucionario ya que se desligaba de los poderes fácticos envueltos en conflictos. 
"En las condiciones específicas de la época, la juridización autónoma de la resolución de los conflictos y la centralidad de la argumentación jurídica permitieron una regulación social que no perdía de vista objetivos emancipadores." ${ }^{\prime 69}$

Los pandectistas en el siglo XIX transformarían el derecho romano en una estructura formal y jerarquizada de reglas jurídicas que obedecía a un rígido sistema lógico. La ciencia jurídica se transformó en matemática. Si el proyecto emancipador estaba del lado de una burguesía emprendedora, una vez conquistado el poder político, el proyecto se hundió.

Otra tensión entre regulación y emancipación se manifiesta en las teorías del contrato social, de las cuales para Santos, la más importante es la de Rousseau. Esto está en concordancia con lo hasta aquí expuesto, pues no se olvide que una de las ideas rescatables por la nueva teoría crítica es la de comunidad, es decir, la que tiene a Rousseau como mentor.

Rousseau es un crítico de las Luces dentro de las Luces. Crítico implacable de la ciencia moderna, es el que mejor expresa la tensión antes mencionada. La pregunta básica del ginebrino es: ¿cómo es posible crear una obligación política basada en la libertad? ¿cómo actuar de forma que se maximice la libertad? La solución es la voluntad general, que nunca debe ser confundida con la voluntad de todos ${ }^{70}$.
La voluntad general es la síntesis entre regulación y emancipación y la figura del ciudadano, mezcla de rey y súbdito, la atestigua.

Rousseau concibe el derecho tanto como principio ético como eficaz instrumento para la ordenación y transformación sociales. Por un lado, el Estado es todopoderoso: está potenciado por la voluntad general; pero, por otro, es indistinguible de los ciudadanos. No es esto lo que se deriva del contrato social de Hobbes.

En Hobbes la soberanía del Estado es absoluta y por eso, mientras Rousseau potenciaba la idea moderna de comunidad, aquél potencia la de Estado. No se trata ya de crear una sociedad civil basada en la libertad e igualdad. Lo que se juega en esta sociedad es la paz y ésta sólo está garantizada cuando el soberano es absoluto, es decir, desligado de sus propias leyes ${ }^{71}$. Y así, el término que resume el pacto entre soberano y súbdito es el de sumisión $^{72}$. La política se separa de la ética y la moral se privatiza. Concluye Santos:

"Es evidente que el pensamiento de Hobbes transporta las simientes de la estatalización como forma empobrecida de la regulación moderna." 73

Locke va a representar el tercer principio de la modernidad, el principio "mercado". Para él, el gobierno es legítimo mientras respete los derechos naturales y sólo existe para protegerlos. Lo que se gana por 
abandonar un estado de naturaleza, muchísimo menos siniestro que el de Hobbes, y entrar en sociedad, es un procedimiento para resolver pacíficamente conflictos relacionados con la propiedad.

Santos ve en Locke el origen de las relaciones modernas de mercado tal y como fueron universalizadas por el capitalismo: el trabajo como fuente de propiedad; la propiedad potencialmente ilimitada y legíti$\mathrm{ma}^{74}$; el Estado legitimado por la seguridad que puede conferir a las relaciones de propiedad.

Vista la tensión entre regulación y emancipación en las teorías del contrato social y anticipando lo que Santos Ilamará "capitalismo desorganizado" (él mismo lo matizará después), podemos preguntarnos qué principio prevalece hoy en nuestra sociedad. La contestación es simple: el de mercado. Y la respuesta es simple: si seguimos con detenimiento el análisis de las teorías políticas del siglo XVII y que serían la base de las sociedades democrático-liberales, encontramos una serie de constantes según C. B. Macpherson ${ }^{75}$ :

1.- Lo que hace humano a un hombre es ser libre de la dependencia de la voluntad de los demás.

2.- La libertad de la dependencia de los demás significa libertad de cualquier relación con los demás salvo aquéllas en las que el individuo entra voluntariamente por su propio interés.
3.- El individuo es esencialmente el propietario de su propia persona y de sus capacidades, por las cuales nada debe a la sociedad.

4.- Aunque el individuo no puede alienar toda su propiedad sobre su propia persona, puede alienar su capacidad para trabajar.

5.- La sociedad humana consiste en una serie de relaciones mercantiles.

6.- La libertad de cada individuo sólo puede limitarse justamente por unas obligaciones y reglas tales que sean necesarias para garantizar la misma libertad de los demás.

7.- La sociedad política es una invención humana para la protección de la propiedad que el individuo tiene sobre su propia persona y sobre sus bienes, y para el mantenimiento de relaciones de cambio debidamente ordenadas entre individuos considerados como propietarios de sí mismos.

En resumen, las sociedades se asientan en la figura del individualismo posesivo, figura que está en la base del neoliberalismo en esta época de globalización que Santos estudia.

\section{La modernidad jurídico-política y el capitalismo}

Tres van a ser los períodos que Santos va a considerar. El primero cubre el siglo XIX. El segundo concluye en las dos primeras décadas de la post-guerra; y el tercero, el del "capitalismo desorganizado", 
comienza en los sesenta y hoy continúa. Y las conclusiones que extrae nuestro autor son las siguientes:

El primer período "muestra que el proyecto sociocultural de la modernidad es demasiado ambicioso e internamente contradictorio". El segundo, trata de minimizar sus fracasos cumpliendo algunas de sus promesas. El tercero presenta tres características principales: a) lo conseguido por la modernidad no es irreversible y debe ser preservado, aunque la misma modernidad no pueda garantizarlo; b) las promesas no cumplidas seguirán incumplidas mientras domine el paradigma moderno; y c) el déficit, irreversible, es mayor de lo que se creía. Lo que en el fondo no es sino analizar el comportamiento del binomio regulaciónemancipación a la luz del derecho estatal moderno. Veamos esto con un poco más de detenimiento.

\section{Primer período}

Sin perder de vista el binomio regulación-emancipación, Santos afirma que el Estado constitucional del siglo XIX minimiza los ideales éticos para ajustarlos a los intereses del capitalismo; la soberanía del pueblo se transforma en soberanía del Estado-nación; la voluntad general en la regla de la mayoría y en la razón de Estado; el derecho se convierte en un dócil instrumento de la construcción nacional y de regulación del mercado; y, por último, el buen orden se transforma en orden sin más. ¿Cómo pudieron darse estas transformaciones?
"La aparición del positivismo en la epistemología de la ciencia moderna y del positivismo jurídico pueden considerarse construcciones ideológicas destinadas tanto a reducir el progreso social al desarrollo capitalista, como a inmunizar la racionalidad contra la contaminación de cualquier irracionalidad no capitalista, sea la divina, la religiosa, la tradicional, la metafísica o la ética, o incluso, las utopías o ideales emancipadores. En el mismo proceso, las irracionalidades del capitalismo pasan a coexistir y hasta convivir con la racionalidad moderna, si se presentasen como regularidades empíricas." ${ }^{176}$

Como se observa ya desde el primer período, el fin de este Estado constitucional, basado en el derecho, se muestra desde el primer momento como garante del "orden" pues su racionalidad permite prever y por tanto controlar. Estamos pues ante un proyecto manifiesto de ingeniería social. Y esta dominación está legitimada por leyes universales y abstractas emanadas del Estado, y esto permite pasar de la dominación política a la técnico jurídica. Así, más adelante, Santos nos advierte de que este Estado mínimo del constitucionalismo liberal no sólo contiene en sí mismo las simientes del Estado providencia - período segundo que veremossino también las del Estado fascista y estalinista.

Pero este orden, basado en un derecho formal negativo, no consiguió ocultar las muchas tensiones 
que generó, pues hay que recordar que el siglo XIX los proyectos utópicos y socialistas emergieron con fuerza para denunciar simplemente que lo que se presentaba como orden no era sino fuerza ${ }^{77}$.

Segundo período

A finales del siglo XIX, el panorama se alteró debido al creciente dominio del modo de producción capitalista. Si en el período anterior la separación Estado-sociedad civil era nítida, a partir de ahora dicha separación se hará más tenue; las externalidades generadas por el modo de producción y el crecimiento impresionante de las grandes empresas, capaces de controlar el poder político, obligarán al Estado a intervenir en ámbitos antes desconocidos. El principio Estado y el principio mercado convergen para que los conflictos sociales puedan ser institucionalizados.

"La gestión económica (keynesianismo) y la gestión pública (Estado providencia) del capitalismo en los países centrales condujeron a un nuevo modo de regulación que se designó como fordismo.."78

De esta manera, tal y como Santos afirmaba al comienzo, solidaridad justicia e igualdad podían ser compatibles con autonomía, identidad y libertad siempre que no se pusiera en tela de juicio el modo de producción capitalista, es decir, que gracias al gasto público se podían desarrollar políticas sociales que permitían cumplir algunas de las promesas del proyecto moderno.
Claro que por otro lado se pasó de la revolución al reformismo y de ahí a la marginalización de los partidos comunistas y a la reconversión de los partidos socialistas en socialdemócratas.

"De modo general, a medida que el Estado se implica en la gestión de los procesos económicos y sociales, el derecho del Estado se vuelve menos formalista y menos abstracto; el equilibrio y el compromiso entre los intereses en conflicto se hace más evidente (la "materialización" del derecho); y la función de integración política y social del derecho distributivo pasa a ser un tema importante de debate político (la "politización" del derecho)."79

Todo esto supondrá una intensificación de la instrumentalidad del derecho cuyas consecuencias no se harán esperar: colonización de la sociedad, sobre socialización e ineficacia.

"La creciente complejidad de los subsistemas sociales y la creciente necesidad de coordinación social y de integración entre ellos exigían un campo jurídico potencialmente infinito, donde los déficits y los excesos del desarrollo económico y social fuesen, si no eliminados, por lo menos reducidos a proporciones controlables. Esta utopía jurídica simbolizaba, antes que nada, un nuevo concepto de caos social, y simétricamente un nuevo concepto de orden." ${ }^{\prime 80}$

Si en algún momento se pensaba que algunas promesas como un 
sistema de distribución más justo o un sistema democrático eran ya realidades, pronto se vería, como afirmaba Santos, que estos logros no eran irreversibles.

Tercer período

Al tercero, Santos lo califica como el período de "capitalismo desorganizado", pero rápidamente aclara lo que ello significa:

"Sin embargo esta designación es ambigua y traicionera, pues puede hacer creer que en el período actual el capitalismo no está organizado, lo que está lejos de ser verdad. De hecho, puede afirmarse lo contrario, que el capitalismo está más organizado que nunca. La expresión "capitalismo desorganizado" significa en primer lugar que las formas de organización típicas del segundo período están siendo gradualmente desmanteladas o reconstituidas en un nivel de coherencia mucho más bajo, $y$, en segundo lugar, que precisamente a causa de ese proceso, es mucho más visible la demolición de las antiguas formas organizativas que el propio perfil de las nuevas formas que van a sustituirlas. "81

No es pues desorden sino un nuevo orden que aún no percibi$\operatorname{mos}^{82}$. Lo que sí podemos constatar es que el principio mercado es el que ha tomado el principal protagonismo ${ }^{83}$.

Para comenzar no puede prescindirse de la escala mundial en el que todo este proceso se desarrolla y así vemos cómo el sistema interestatal atraviesa una fase de profundas transformaciones, pero éstas son diferentes en tanto hablemos de Estados centrales o periféricos.

"En un contexto de creciente desigualdad entre el Norte y el Sur, los Estados periféricos y semi-periféricos están siendo limitados — como víctimas o como colaboradores-al cumplimiento de las determinaciones del capital financiero e industrial transnacional; determinaciones a su vez establecidas por las organizaciones internacionales controladas por los estados centrales. Estas determinaciones, frecuentemente presentadas en combinaciones extrañas de liberalismo económico y protección de los derechos humanos, sacuden hasta tal punto el de por sí ya frágil componente social del Estado, que esos países asumen la idea de la crisis del Estado providencia sin haberse aprovechado nunca de él." ${ }^{14}$

De todo esto, aunque Santos limita sus efectos, el principio que más ha sido dañado es el de comunidad. Entonces la pregunta sería ¿cómo recobrarlo? ¿Es rescatable ese Estado providencia ${ }^{85}$ ? La respuesta de Santos es:

"La idea no consiste en mirar a un pasado que probablemente nunca existió, sino encarar la creación futura de un tercer sector, situado entre el Estado y el mercado que organice la producción y la reproducción de forma socialmente útil a través de movimientos sociales y organizaciones no gubernamentales, en nombre de la nueva solidaridad dictada por los nuevos riesgos con- 
tra los cuales ni el Estado postintervencionista ni el mercado ofrecen garantías." ${ }^{\prime 86}$

Tras este recorrido podemos concluir que el derecho moderno reducido a un derecho estatal científico fue eliminando la tensión entre regulación y emancipación que originariamente era para él constitutiva $^{87}$. En el primer período, la emancipación fue sacrificada y confinada en la actividad de los movimientos antisistémicos. En el segundo - recuérdese reformismo frente a revolución-, los proyectos emancipadores se subordinaron a los reguladores. Y en el tercero, lejos de emerger los proyectos emancipadores con el desmantelamiento de la regulación fordista, simplemente se desintegraron ellos también. Hace falta por tanto comenzar por "des-pensar" el derecho.

Pero antes de concluir hay un punto que debiéramos considerar. Si debemos "des-pensar" el derecho será porque éste no ha cumplido los objetivos asignados, la emancipación simplemente ha desaparecido en aras de un orden-desorden. Pero una vez aquí, ¿podemos sorprendernos del resultado?

A lo largo de la exposición se echa de menos a un interlocutor que dedicó también páginas a esta materia: el Estado de derecho. El interlocutor ausente es Walter Benjamin. Recordemos un fragmento de su octava tesis Sobre el concepto de historia:

"La tradición de los oprimidos nos enseña que el estado de excep- ción en que vivimos es la regla. (...) No tiene nada de filosófico asombrarse de que las cosas que estamos viviendo sean "todavía" posibles en pleno siglo XX." ${ }^{\prime 88}$

"Estado de excepción" y "asombro". El concepto de "Estado de excepción" lo tomó prestado C. Schmitt de Donoso Cortés y lo convirtió en centro de su teoría política. Se podría definir como la suspensión de todo el orden existente, es esto justamente lo que caracteriza al soberano: convertir su decisión en ley. De todos modos, como bien matiza Reyes Mate, se trata de un concepto muy particular:

"Estamos ante un concepto escurridizo porque si, por un lado, significa la suspensión del derecho vigente, eso no quiere decir por otro que el suspendido que de libre de toda norma o desligado del derecho. Al contrario, queda a merced del poder pero sin mediación de norma alguna; sigue vigente la fuerza de la ley, pero sin la formalidad de la ley, con lo que el derecho queda dependiendo de la pura decisión del soberano." ${ }^{199}$

Si la violencia en las sociedades actuales es para Santos lo que le motiva para llevar a cabo una crítica radical, crítica que, como hemos visto recae no única pero fundamentalmente en el derecho, será porque derecho y violencia parecen caminar juntos.

"La violencia crea el derecho y lo mantiene violentamente. Esta naturaleza del derecho contamina la 
política ya que el derecho es la institucionalización de la política. (...) Si la violencia le viene a la política del derecho, lo que procedería entonces es la suspensión del derecho para acabar con la violencia." ${ }^{\prime 90}$

Quizá estemos tentados de concluir que la meditación benjaminiana sobre el Estado de excepción es producto de la época en que vivió, el nazismo, pero nada más lejos de la verdad. Sus afilados dardos se dirigen ni más ni menos que contra el Estado de Derecho. Recuérdense las afirmaciones del propio Santos en el primer período sobre el Estado mínimo constitucional, de él emanaba hasta el fascista. ¿No va ligada la Revolución francesa a la época de las Luces? ¿Cómo entonces pudo degenerar en el Terror siendo éste legitimado por el derecho revolucionario? Santos nos dirá que la Revolución Francesa será la última porque queda sometida completamente al derecho, esto es,

"Después de la consolidación, el nuevo derecho revolucionario tiene que ser protegido contra el peligro de una nueva ruptura; los cambios futuros tiene que limitarse a transformaciones normales." ${ }^{\prime 91}$

En resumen, cualquier revolución queda sin derecho, así que no sólo vivimos una época postrevolucionaria sino contrarrevolucionaria. $\mathrm{Y}$ esto no es para asombrarse.

\section{Para comenzar a des-pensar}

Tal y como lo ha presentado Santos, el derecho ha desempeñado un papel fundamental en la gestión reconstructiva de los excesos y déficits de la modernidad, pero ¿no es legítimo pensar que la crisis del paradigma epistemológico acarree una crisis del paradigma jurídico? Pero ¿por qué "des - pensar"?

Según Wallerstein, las ciencias sociales —la sociología, la economía y la ciencia política- fueron tres de las principales fuentes de conocimiento que permitieron a la ideología liberal legitimar su posición porque dichas ciencias le permitían presentar las leyes de transformación pacífica de la sociedad, es más, como luego se verá, tras la revolución, ésta ya es "imposible". Si estas ciencias eran la base del paradigma de la modernidad, en un momento de transición paradigmática, la tarea que se impone es despensarlas. Así, Wallerstein afirma:

"Sin embargo además de repensar las ciencias sociales del siglo XIX, creo que necesitamos impensarlas debido a que muchas de sus suposiciones - engañosas y constrictivas desde mi punto de vista- están demasiado arraigadas en nuestra mentalidad. Dichas suposiciones, otrora consideradas liberadoras del espíritu, hoy en día son la principal barrera intelectual para analizar con algún fin útil el mundo social." 92

Mundo social que, como repite Santos, siguiendo a Wallerstein, está en transformación; pero ¿cómo interpretarla?

Para Santos hay cuatro formas de abordarla: 
Para la primera, el capitalismo y el liberalismo triunfaron. Así estamos en el fin de la historia, conocemos su secreto por fin, y en el fin de las ideologías ${ }^{93}$. Otra interpretación considera que la modernidad es un proyecto inacabado con capacidad aún de transformación social. Una tercera ve la definitiva victoria del capitalismo, sistema que se expandirá de una forma postmoderna. Y, por fin, una última que considera que esta crisis abre un abanico de posibilidades siendo una de ellas la consecución de una sociedad no capitalista y eco-socialista. ${ }^{94}$

Obviamente será la última la considerada por Santos y no podía ser de otro modo. Las contradicciones en tiempos normales, cuando se manifiestan como excesos o déficits, pueden ser tratadas con los recursos intelectuales disponibles en ese momento; pero cuando los tiempos cambian, el sistema sufre una crisis de deslegitimación global. Por eso en la lucha paradigmática lo que está en juego es una utopía cuya eficacia estriba en los recursos intelectuales y políticos que proporciona a las luchas subparadigmáticas.

Si esto es así, ya podemos entender que el concepto de transición paradigmática que aquí se defiende es muy amplia: es una transición que va más allá de los modos de producción y que apunta a la socialidad.

"Cuando el sistema mundial se convierte en unidad privilegiada de análisis, el conocimiento de su lógi- ca global, de su desarrollo y de sus crisis se vuelve algo fundamental para comprender las manifestaciones locales que van aflorando por todo el sistema interestatal. Admitiendo que el sistema mundial es la unidad privilegiada del desarrollo histórico moderno y, consecuentemente, su unidad de análisis privilegiada, el debate sobre la transición paradigmática debe realizarse en el plano del sistema mundial." ${ }^{\prime 95}$

¿Dónde queda entonces el Estado? No queda más remedio que repensarlo $\mathrm{o}$, mejor dicho, despensarlo. Debemos separar Estado y derecho. El Estado nunca ostentó el monopolio del derecho, pues se sirvió de medios legales e ilegales dependiendo de su posición en el sistema mundial. Por otro lado, al rechazar la pluralidad de órdenes jurídicos anuló el poder emancipador del derecho moderno ${ }^{96}$. Así pues,

"El proceso de despensar el derecho moderno se orientará inicialmente por las tradiciones prohibidas o marginadas de la modernidad, lo que requiere alguna excavación arqueológica. " ${ }^{197}$

Pero además el derecho tenía otra función: si a las ciencias sociales competía descubrir las regularidades y causas del cambio social, el derecho tansformaría dichas regularidades en regulaciones jurídicas eficaces. Todos los futuros eran posibles siempre y cuando estuvieran enmarcados en el sistema capitalista. Es decir, estamos ante lo que se podría denominar "cambio social 
normal", basado en la repetición y en la mejoría, y que desarrollaría tres estrategias: acumulación de recursos, hegemonía y confianza. En resumidas cuentas, lo que queda definitivamente expulsado es el espíritu revolucionario ${ }^{98}$. Pero hay un problema con este modelo.

"La imposibilidad de sustentar a escala global un bienestar social mercantilizado, junto al agravamiento de las desigualdades sociales, la transformación de los valores culturales en una dirección postmaterialista y la creciente visibilidad social de formas de opresión hasta ahora ocultas, todo esto contribuye a cuestionar, a un nivel fundamental, la calidad y la cantidad de vida producida por la transformación normal. En verdad cada vez se considera más anormal la transición normal. Finalmente, debido a la discrepancia entre la capacidad de acción y la capacidad de previsión, los riesgos, sobre todo los provocados por intervenciones tecnológicas y ambientales, de consecuencias cada vez más imprevisibles, se han multiplicado cada vez más descontroladamente en términos de escala y de frecuencia." ${ }^{\prime 99}$

Por todo lo expuesto, la tarea de despensar parece urgente y necesaria. Pero como dice Santos, la tarea de despensar es epistemológicamente compleja porque conlleva una deconstrucción total, mas no nihilista, y una reconstrucción discontinua, pero no arbitraria.

"Junto a esto, al ser efectuada siguiendo el rastro de la ciencia moderna, el momento destructivo del proceso de despensar tiene que ser disciplinar (el derecho y cada una de las ciencias sociales), al paso que su momento constructivo debe ser no disciplinar: el proceso de despensar equivale a una nueva síntesis cultural." 100

Hasta aquí la crítica. Pasemos ahora a la nueva epistemología que, obviamente, será también crítica. Y así será porque frente a la "ceguera" se opondrá la "visión".

\section{Para una epistemología de la visión}

/ / Si desde la forma hegemónica de conocimiento, conocemos creando orden, la epistemología de la visión plantea la cuestión sobre si es posible conocer creando solidaridad. "101

Esta es la pregunta clave porque la solidaridad apunta a un reconoci- miento de igualdad y a un respeto por saberes que han quedado marginados al igual que sus portadores, de ahí que vayamos hacia los conocimientos ausentes. Dado que Santos desarrolla sus tesis con más detalle en su texto "El milenio huérfano", a él dirigiremos nuestra atención. 


\section{Crítica de la razón metonímica}

La razón se manifiesta como metonímica en tanto que totalizadora. Como nada existe fuera de ella, se afirma entonces como exhaustiva, exclusiva y completa. Además, ninguna de las partes puede ser pensada al margen de la totalidad. Debe recordarse en este momento que Santos ve siempre la totalidad desde la epistemología y no desde la ontología, al contrario que la razón metonímica. Si ésta es la razón que imperó en la modernidad, para Santos está claro que con ella no sólo tenemos una limitada comprensión del mundo sino que ella misma se autocomprende muy limitadamente. $Y$ esto tiene consecuencias inmediatas.

Por esta limitada autocomprensión, la razón metonímica se impone en el mundo sin argumentación por su carencia de fundamentos; no da razones de sí, se impone como dice Santos simplemente por la eficacia de su imposición.

"Fundada en la razón metonímica, la transformación del mundo no puede ser acompañada por una adecuada comprensión del mundo. Esa inadecuación significó violencia, destrucción y silenciamiento para todos los que, fuera de Occidente, fueron sometidos a la razón metonímica; y significó alineación, "malaise" y "uneasiness" en el propio Occidente." 102

Esta brutal reducción de los mundos a un mundo y de los tiempos a un tiempo acarreó un empobreci- miento de la experiencia entendida en términos benjaminianos, empobrecimiento que no es debido a una carencia sino a una intolerable arrogancia. Entonces ya se puede vislumbrar la propuesta de Santos: una ampliación del mundo y una dilatación del presente. ¿Cómo recorrer este camino? Mediante lo que el autor denomina "sociología de las ausencias"

"El objetivo de la sociología de las ausencias es transformar objetos imposibles en posibles, y basándose en ellos, las ausencias en presencias, centrándose en los fragmentos de la experiencia social no socializados por la razón metonímica. ¿Qué existe en el Sur que se escapa a la dicotomía Norte-Sur?."103

¿Cómo recuperar estas ausencias o no existencias reprimidas y marginadas? Con cinco lógicas. Veámoslas a continuación.

La primera deriva de la monocultura del saber y del rigor del saber, el modo de producción de ausencias más potente. Esto requiere una transformación radical de este canon pues condena a la ignorancia a quien no se somete a él, y ya sabemos que para Santos no hay conocimiento total ni ignorancia total.

La segunda se basa en la monocultura del tiempo lineal, la Historia tiene un sentido único ya conocido. Este canon esconde una peligrosísima idea de "Progreso" que sataniza a quienes dudan de él.

La tercera es la lógica de la clasificación social de la que de- 
rivan las diferencias por sexo, por raza, etc., lo que desemboca en la dicotomía superior e inferior de gravísimas consecuencias.

La cuarta es la lógica de la escala dominante, otra forma de afirmar un único mapa donde sólo hay una ubicación y una orientación.

Y por último la quinta. La lógica productivista, en otros términos, la lógica capitalista y sus dogmas irrefutables: el crecimiento económico y criterio de productividad.

El reto no puede ser otro que combatir estas cinco perversas lógicas de dominación y ampliar el mundo, pues, haciéndolo, dilatamos el presente con lo que aumentan nuestras posibilidades para el futuro. En resumen, esta sociología de las ausencias es contrafáctica, subversiva y transgresiva, y es justamente el inconformismo que de ella se sigue, el que nos conduce a las siguientes tomas de posición que enfrentan las lógicas apuntadas una a una. Así, frente a la primera, se defenderá una ecología de los saberes; frente a la segunda, una ecología de las temporalidades; frente a la tercera, una ecología de los reconocimientos; frente a la cuarta, una ecología de las trans-escalas; y, por último, frente a la quinta, una ecología de la productividad.

"La deconstrucción asume cinco formas, correspondientes a la crítica de las cinco lógicas de la razón metonímica, o sea, des-pensar, des-residualizar, des-espacializar, des-localizar y des-producir." ${ }^{104}$
Pero no es la razón metonímica la única causante del desperdicio de la experiencia, también la razón proléptica contribuye a ello en gran medida.

\section{Crítica de la razón proléptica}

Como decíamos con la razón proléptica ("prolepsis": conocimiento anticipado de algo) seguimos en dentro del estrechamiento del presente y por lo tanto del desperdicio de la experiencia. La razón proléptica "es la parte de la razón indolente que concibe el futuro a partir de la monocultura del tiempo lineal". Es decir, el tiempo vacío y homogéneo que ya denunciara W. Benjamin.

"El futuro es de esta manera infinitamente abundante e infinitamente igual, un futuro que, como señala Marramao, sólo existe para tornarse en pasado. Un futuro concebido de ese modo no tiene cómo ser pensado, y en esto se fundamenta la indolencia de la razón proléptica." 105

Si la dilatación del presente se consigue a través de la sociología de las ausencias, la contracción del futuro se logra mediante una sociología de la emergencias. Con ella surge un futuro de posibilidades plurales y concretas, simultáneamente utópicas y realistas, que se construyen en el presente. Estamos pues en el "todavía no" que E. Bloch desarrolla en su magna obra El principio esperanza. El "no" no es sólo una falta, es eso unido a la voluntad de superarlo, es decir "sí" a algo diferente. $\mathrm{Y}$ esto debe ser 
entendido en términos de "teoría de la información". Si estamos reflexionando sobre lo nuevo, pensemos qué significa esto. En teoría de la información, lo nuevo es lo improbable, no lo imposible. Si apostamos por lo nuevo, el tiempo vacío y homogéneo se empieza a preñar de posibilidades, el futuro no está hoy ya escrito - "Sólo anticipas desastres", le dice un enojado Agamenón a Calcante en La llíada-. Se trata de una posibilidad incierta $-y$ esto es importantísimo en la teoría de Santos-, pero nunca neutra, puede ser la posibilidad de la salvación o utopía o del desastre. Conviene recordar aquí que la obra de Santos refleja un optimismo trágico; optimismo porque no debemos postrarnos ante los hechos desconociendo las posibilidades que la realidad brinda; trágico porque dichas posibilidades son de distinto signo y conviven.

"Al dilatar el presente y contraer el futuro, las sociologías de las ausencias y de las emergencias, cada una a su manera, contribuyen a desacelerar el presente otorgándole un contenido más denso y sustantivo que al instante fugaz entre pasado y futuro al que la razón proléptica lo condenó."106

¿En qué campos se enriquecerá la experiencia con la ayuda de estas sociologías?

En el campo del conocimiento: biodiversidad, justicia, agricultura, etc.. En el del desarrollo, trabajo y producción. En el del reconocimiento. En el de la democracia. Y por último, en el de la información y comunicación.

\section{Una tarea hermenéutica: la tra- ducción}

¿Cómo se puede hablar de transformación social después de haber reconocido la extremada complejidad del mundo? ¿Es posible una teoría general? ¿Qué nos mueve a pensar que un mundo mejor es posible? ¿Cuál es el sentido de las luchas por la emancipación? A estas preguntas Santos responde con el trabajo de la traducción.

"La traducción es el procedimiento que permite crear inteligibilidad recíproca entre las experiencias del mundo, tanto las disponibles como las posibles, reveladas por la sociología de las ausencias y la sociología de las emergencias. Se trata de un procedimiento que no atribuye a ningún conjunto de experiencias ni el estatuto de totalidad ni el estatuto de totalidad exclusiva ni el estatuto de parte homogénea."107

Precisemos más siguiendo a Santos.

"La traducción entre saberes asume la forma de una hermenéutica diatópica. Ésta consiste en un trabajo de interpretación entre dos o más culturas con el objetivo de identificar preocupaciones isomórficas entre ellas y las diferentes respuestas que proporcionan."108

Esta idea es muy reveladora pues muestra la coherencia del pensamiento de Santos: no hay una teoría 
englobante — "la teoría general de la imposibilidad de una teoría general" - dada la complejidad de la realidad pero sí hay una forma de administrarla. Es más, ninguna cultura es completa lo que significa que siempre podrá ser enriquecida por el diálogo y la confrontación con otras culturas, lo que Santos denomina universalismo negativo.

Pero la traducción no se da únicamente entre saberes, sino también entre las prácticas sociales y sus agentes y esto es fácilmente comprensible si tenemos en cuenta que tanto la sociología de las ausencias como la de las emergencias aumentan el número de experiencias sociales de los agentes. Pero además, y esto está en sintonía con lo expuesto, al no haber un principio único de transformación social, la traducción hace posible la inteligilibilidad de las prácticas, su evaluación y la definición de posibles alianzas entre ellas.
"El trabajo de traducción tiende a esclarecer lo que une y lo que separa los diferentes movimientos y las diferentes prácticas, de modo que determine las posibilidades y los límites de la articulación entre ellos. Dado que no hay una práctica social o un sujeto colectivo privilegiado en abstracto para conferir sentido y dirección a la historia, el trabajo de traducción es decisivo para definir en concreto, en cada momento y contexto histórico qué constelaciones de prácticas tienen un mayor potencial contra-hegemónico."109

En resumen, lo que subyace al trabajo de la traducción es el reconocimiento de la complejidad de la realidad así como el modo de afrontarla de los distintos agentes sociales. Y esta complejidad se va a manifestar de nuevo cuando Santos aborde los modos de producción del poder, del derecho y del sentido común.

\section{Los modos de producción del poder, del derecho y del sentido común}

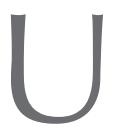

na teoría crítica de la sociedad como la que presenta Santos, debe comenzar por mostrar las insuficiencias de las anteriores, y esto es precisamente lo que hace nuestro autor. Tras pasar revista al marxismo, a Foucault y al feminismo, Santos presenta un mapa estructura-acción no sin antes informar de que las sociedades capi- talistas son constelaciones políticas, jurídicas y epistemológicas y cada una de ellas genera seis modos de producción del poder, seis modos de producción del derecho y seis modos básicos de producción de conocimiento. Este planteamiento analítico obviamente se verá superado en la práctica ya que si bien cada modo se presenta como 
autónomo no por ello deja de estar interrelacionado con los demás. Además, antes de entrar en el mapa, Santos define el poder como cualquier relación social regulada por un intercambio desigual.

"En lo relativo a las relaciones de poder, lo que es más característico de nuestra sociedad es la constatación de que la desigualdad material está profundamente entrelazada con la desigualdad no material, sobre todo con la educación desigual, la desigualdad de las capacidades representacionales/ comunicativas y expresivas, y también la desigualdad de oportunidades y de capacidades para organizar intereses y para participar autónomamente en procesos de toma de decisiones significativas. "110

Vayamos al mapa estructuraacción.

\begin{tabular}{|c|c|c|c|c|c|c|}
\hline $\begin{array}{l}\text { DIMEN- } \\
\text { SIONES / } \\
\text { ESPACIOS } \\
\text { ESTRUC- } \\
\text { TURALES }\end{array}$ & $\begin{array}{c}\text { UNIDAD DE } \\
\text { PRÁCTICA } \\
\text { SOCIAL }\end{array}$ & $\begin{array}{l}\text { INSTITU- } \\
\text { CIONES }\end{array}$ & $\begin{array}{l}\text { DINÁMICA } \\
\text { DE DESA- } \\
\text { RROLLO }\end{array}$ & $\begin{array}{c}\text { FORMA } \\
\text { DE } \\
\text { PODER }\end{array}$ & $\begin{array}{l}\text { FORMA DE } \\
\text { DERECHO }\end{array}$ & $\begin{array}{l}\text { FORMA } \\
\text { EPISTEMO- } \\
\text { LÓGICA }\end{array}$ \\
\hline $\begin{array}{l}\text { ESPACIO } \\
\text { DOMÉSTI- } \\
\text { CO }\end{array}$ & $\begin{array}{l}\text { Diferencia } \\
\text { sexual y } \\
\text { generacional }\end{array}$ & $\begin{array}{l}\text { Matrimo- } \\
\text { nio familia } \\
\text { y paren- } \\
\text { tesco }\end{array}$ & $\begin{array}{l}\text { Maximiza- } \\
\text { ción de la } \\
\text { afectividad }\end{array}$ & Patriarcado & $\begin{array}{l}\text { Derecho } \\
\text { doméstico }\end{array}$ & $\begin{array}{l}\text { Cultura } \\
\text { familiar }\end{array}$ \\
\hline $\begin{array}{l}\text { ESPACIO } \\
\text { DE PRO- } \\
\text { DUCCIÓN }\end{array}$ & $\begin{array}{l}\text { Clase y } \\
\text { naturaleza } \\
\text { como } \\
\text { naturaleza } \\
\text { capitalista }\end{array}$ & $\begin{array}{l}\text { Fábrica y } \\
\text { empresa }\end{array}$ & $\begin{array}{l}\text { Maximi- } \\
\text { zación del } \\
\text { lucro y maxi- } \\
\text { mización de } \\
\text { la degrada- } \\
\text { ción de la } \\
\text { naturaleza }\end{array}$ & $\begin{array}{l}\text { Explo- } \\
\text { tación y } \\
\text { naturaleza } \\
\text { capitalista }\end{array}$ & $\begin{array}{l}\text { Derecho de } \\
\text { la produc- } \\
\text { ción }\end{array}$ & $\begin{array}{l}\text { Producti- } \\
\text { vismo, tec- } \\
\text { nologismo, } \\
\text { formación } \\
\text { profesional } \\
\text { y cultura } \\
\text { empresarial }\end{array}$ \\
\hline $\begin{array}{l}\text { ESPACIO } \\
\text { DE MER- } \\
\text { CADO }\end{array}$ & $\begin{array}{l}\text { Cliente, con- } \\
\text { sumidor }\end{array}$ & Mercado & $\begin{array}{l}\text { Maximiza- } \\
\text { ción de la } \\
\text { utilidad y } \\
\text { maximiza- } \\
\text { ción de la } \\
\text { mercantiliza- } \\
\text { ción de las } \\
\text { necesidades }\end{array}$ & $\begin{array}{l}\text { Fetichismo } \\
\text { de las mer- } \\
\text { cancías }\end{array}$ & $\begin{array}{l}\text { Derecho } \\
\text { del inter- } \\
\text { cambio }\end{array}$ & $\begin{array}{l}\text { Consu- } \\
\text { mismo y } \\
\text { cultura de } \\
\text { masas }\end{array}$ \\
\hline
\end{tabular}




\begin{tabular}{|c|c|c|c|c|c|c|}
\hline $\begin{array}{l}\text { DIMEN- } \\
\text { SIONES / } \\
\text { ESPACIOS } \\
\text { ESTRUC- } \\
\text { TURALES }\end{array}$ & $\begin{array}{c}\text { UNIDAD DE } \\
\text { PRÁCTICA } \\
\text { SOCIAL }\end{array}$ & $\begin{array}{l}\text { INSTITU- } \\
\text { CIONES }\end{array}$ & $\begin{array}{l}\text { DINÁMICA } \\
\text { DE DESA- } \\
\text { RROLLO }\end{array}$ & $\begin{array}{l}\text { FORMA } \\
\text { DE } \\
\text { PODER }\end{array}$ & $\begin{array}{l}\text { FORMA DE } \\
\text { DERECHO }\end{array}$ & $\begin{array}{l}\text { FORMA } \\
\text { EPISTEMO- } \\
\text { LÓGICA }\end{array}$ \\
\hline $\begin{array}{l}\text { ESPACIO } \\
\text { DE LA } \\
\text { COMUNI- } \\
\text { DAD }\end{array}$ & $\begin{array}{l}\text { Etnicidad, } \\
\text { raza, nación, } \\
\text { pueblo y } \\
\text { religión }\end{array}$ & $\begin{array}{l}\text { Comuni- } \\
\text { dad, barrio, } \\
\text { región, } \\
\text { organi- } \\
\text { zaciones } \\
\text { populares } \\
\text { de base, } \\
\text { iglesias }\end{array}$ & $\begin{array}{l}\text { Maximiza- } \\
\text { ción de la } \\
\text { identidad }\end{array}$ & $\begin{array}{l}\text { Diferen- } \\
\text { ciación } \\
\text { desigual }\end{array}$ & $\begin{array}{l}\text { Derecho } \\
\text { de la comu- } \\
\text { nidad }\end{array}$ & $\begin{array}{l}\text { Conoci- } \\
\text { miento } \\
\text { local, cul- } \\
\text { tura de la } \\
\text { comunidad } \\
\text { y tradición }\end{array}$ \\
\hline $\begin{array}{l}\text { ESPACIO } \\
\text { DE LA } \\
\text { CIUDA- } \\
\text { DANÍA }\end{array}$ & Ciudadanía & Estado & $\begin{array}{l}\text { Maximiza- } \\
\text { ción de la } \\
\text { lealtad }\end{array}$ & $\begin{array}{l}\text { Domina- } \\
\text { ción }\end{array}$ & $\begin{array}{l}\text { Derecho } \\
\text { territorial } \\
\text { (estatal) }\end{array}$ & $\begin{array}{l}\text { Naciona- } \\
\text { lismo edu- } \\
\text { cacional } \\
\text { y cultural, } \\
\text { cultura } \\
\text { cívica }\end{array}$ \\
\hline $\begin{array}{l}\text { ESPACIO } \\
\text { MUNDIAL }\end{array}$ & $\begin{array}{l}\text { Estado - } \\
\text { nación }\end{array}$ & $\begin{array}{l}\text { Sistema } \\
\text { interestatal, } \\
\text { organismo } \\
\text { y asocia- } \\
\text { ciones } \\
\text { interna- } \\
\text { cionales, } \\
\text { tratados } \\
\text { internacio- } \\
\text { nales }\end{array}$ & $\begin{array}{l}\text { Maximiza- } \\
\text { ción de la } \\
\text { eficacia }\end{array}$ & $\begin{array}{l}\text { Cambio } \\
\text { desigual }\end{array}$ & $\begin{array}{l}\text { Derecho } \\
\text { sistémico }\end{array}$ & $\begin{array}{l}\text { Ciencia, } \\
\text { progreso } \\
\text { universalis- } \\
\text { ta, cultura } \\
\text { global }\end{array}$ \\
\hline
\end{tabular}

Como se observará, el mapa no hace sino confirmar la compleja realidad ante la que se enfrenta cualquier teoría crítica de la sociedad, tanto por los espacios como por las dimensiones a analizar. $\mathrm{Si}$ ahora volvemos la vista atrás, se comprenderá mejor la postura de Santos: ni el único derecho es el estatal ni la ciencia es la única forma de conocimiento. Recordemos unas palabras de Santos acerca de la transformación de los espejos en estatuas, refiriéndose a las instituciones:
"Cuando esto sucede, la sociedad entra en una crisis que podemos denominar como crisis de la conciencia especular: de un lado la mirada de la sociedad se une al terror de no ver reflejada ninguna imagen que reconozca como suya; de otro, la mirada monumental, fija y opaca del espejo vuelto estatua parece atraer la mirada de la sociedad, no para que ésta vea, sino para que sea vigilada."111

Ya tenemos perfiladas las constelaciones de regulación, ¿es posible encontrar las de emancipación? 


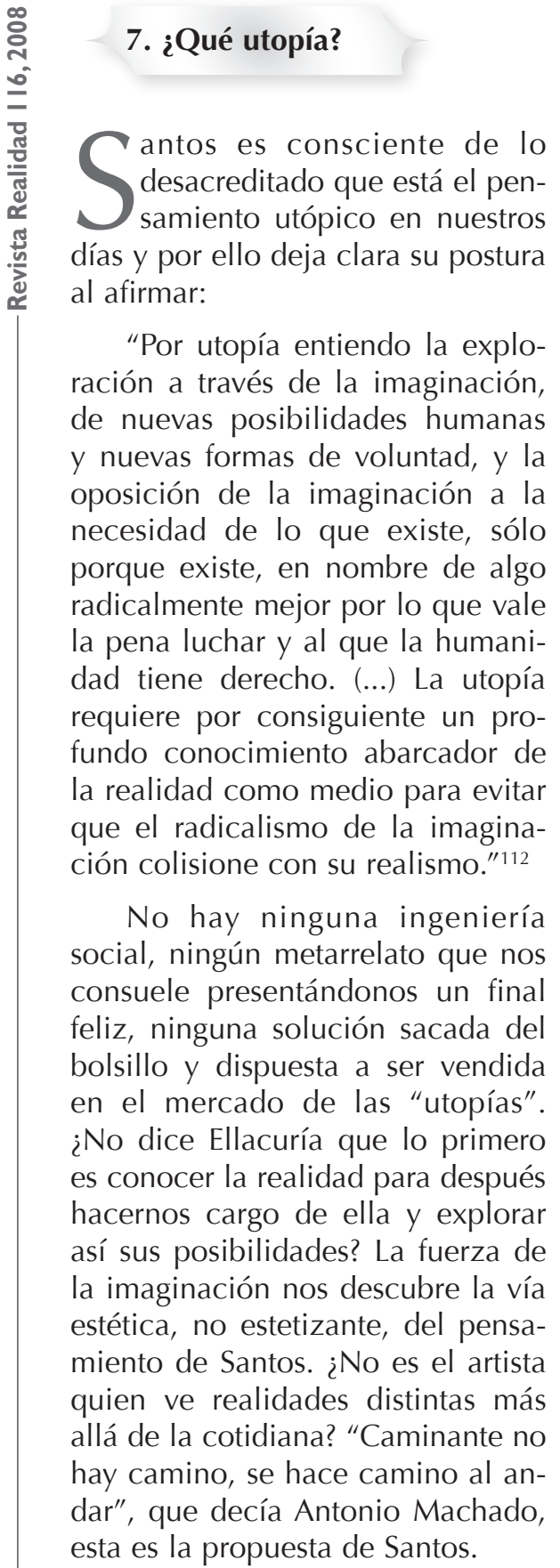

La utopía es para Santos también la arqueología virtual del presente. Leamos estas benjaminianas líneas:

"Su objetivo es excavar únicamente donde nada fue realizado y descubrir por qué, o sea, por qué razón las alternativas dejaron de serlo. En este caso la excavación se interesa por los silenciamientos y por las cuestiones que quedaron por preguntar."113

¿Cómo se "materializa" la utopía? Profundicemos en ella.

Si vamos a movernos, necesitamos nuevos mapas, pero recuérdese $-y$ esto es importante para no caer en contradicción- que éstos siempre son incompletos de ahí el carácter autocrítico de esta teoría de la sociedad.

Así, y con el mapa anterior presente, en el espacio doméstico es necesaria la eliminación de los estereotipos de los papeles de cada sexo. En el de la producción, la creación de valores de uso sin degradar la naturaleza. En el espacio de mercado, la detección de las necesidades radicales que son cualitativas y no cuantificables. En el espacio comunidad, la creación de "comunidades ameba", de identidades múltiples, inacabadas y permeables. En el espacio de la ciudadanía, la extensión del socialismo entendi- 
do como "democracia sin fin. En el espacio mundial, la abolición de la jerarquía Norte-Sur imponiendo un nuevo patrón de sociabilidad transnacional y ecosocialista.

Es evidente que estas transformaciones no van a producirse automáticamente, requieren lucha y ésta, según Santos deberá ser paradigmática, pues la subparadigmáticas tienden a reproducir alguna forma dominante de sociabilidad. La lucha no será cosa de vanguardias sino de grupos inconformistas que rechazan lo que existe sólo porque existe. Y además, estas lucha tendrá lugar dentro y fuera del Estado, un Estado que no será ni el Providencia keynesiano ni el mínimo de los "neoliberales" ni el totalitario. Un Estado que debe ser reinventado, un Estado fuerte que representa una sociedad civil fuerte porque debe canalizar las demandas que de ella le llegan. ¿Esto es todo? No, queda lo más importante.

A una teoría crítica de la sociedad que apuesta por un optimismo trágico se le puede acusar de todo menos de ingenuidad. El párrafo es largo pero vale la pena resaltarlo.

"La lucha paradigmática es en su conjunto altamente arriesgada. Aunque asentada en la contradicción y en la competición, entre lo dominante y lo emergente, lo viejo y lo nuevo, ello no significa que los opresores estén necesariamente y exclusivamente del lado de lo viejo, ni que las víctimas se encuentren necesaria y exclusivamente del lado de lo nuevo y de lo emergente. La mayor parte de los opresores y de las víctimas estará en el paradigma dominante, en relaciones sociales que se concentran alrededor de algunos espacios estructurales, y en el paradigma emergente, en relaciones sociales concentradas alrededor de otros espacios estructurales. Así la experimentación social con formas alternativas de sociabilidad puede ser rechazada por grupos sociales que, en teoría, más se beneficiarían de ella. El derecho de rechazo es, por ello, uno de los derechos incondicionales en la transición paradigmática." ${ }^{\prime 14}$

Y algo más:

"La transición paradigmática es en su conjunto una sociabilidad altamente arriesgada que sólo puede ser llevada a cabo por una subjetividad que sea capaz de correr riesgos y esté dispuesta a correrlos: Una subjetividad emergente." ${ }^{115}$

Éste es el punto que debe ser tratado a continuación: ¿qué tipo de subjetividad se requiere para transitar hacia el paradigma emergente?

No existe este tipo de subjetividad $^{116}$, hay que inventarla también, pero siempre constituida por el "topos" de un conocimiento prudente para una vida decente. Concretemos más.

"La construcción de una subjetividad individual y colectiva, suficientemente apta para enfrentar las futuras competiciones paradigmáticas y dispuesta a explorar las 
posibilidades emancipadoras por ellas abiertas, debe ser guiada a mi entender, por tres grandes "topoi": la frontera, el barroco y el Sur."117

Santos detecta en la frontera las siguientes características: el uso selectivo e instrumental de las tradiciones. El fronterizo vive en suspensión, retiene lo mejor de sus tradición y a la vez espera mejorarla. El fronterizo debe así mismo inventar nuevas formas de sociabilidad, al no ser de ninguna comunidad, debe crearse una forma de vida. No conoce por otro lado jerarquías fuertes y por ello se mueve entre la pluralidad de poderes y ámbitos jurídicos. Al no estar cartografiada de modo adecuado la frontera, el fronterizo vive la fluidez de las relaciones sociales. La vida en la frontera es un constante hacer y deshacer, se multiplica en los márgenes. En resumen, la frontera es la heterotopía; representa el distanciamiento del centro dominante para comprender mejor la opresión que de éste irradia.

La subjetividad será además de fronteriza, barroca. ¿Por qué? Para Santos el barroco representa una época de transición provocada por la crisis, es una forma excéntrica de la Modernidad que al carecer de un poder central constituido permite la vida y la creatividad en la periferia.

La subjetividad barroca invierte en lo local, en lo efímero, en lo transitorio. La interrupción barroca permite la reflexividad, la autorreflexividad, por la ausencia de mapas. Y también la sorpresa.
Con el barroco aparecen la risa y la subversión, en otras palabras, el reencantamiento del mundo.

Y como último "topoi", la subjetividad encargade de transitar hacia el nuevo paradigma emergente, será, digámoslo así, sureña.

Por ser un producto del Imperio, el Sur es el lugar ideal para la excavación. El Sur es el lugar de sufrimiento causado por la modernidad capitalista, son las ruinas, los sueños rotos, lo que nunca emergió, la catástrofe ante la que se horroriza el Ángel de W. Benjamin. El sur es además lo que se opone a ese Norte engreído que se cree único y universal. No deja de ser chocante la respuesta de Habermas, por otra parte digna de elogio, al preguntarle acerca de la universalidad de su teoría de la acción comunicativa y su utilidad para el Sur: "Estoy tentado a responder que no. Soy consciente del hecho de que ésta es una visión limitada y eurocéntrica. Preferiría no tener que responder". Como apunta Santos, la "universalidad" europea deja fuera a cuatro quintos de la población mundial.

\section{La obra de Santos hoy}

La obra de Santos no puede entenderse al margen de su biografía y éste es un punto a resaltar ya que el contacto que ha mantenido permanentemente con la realidad le ha permitido armar una teoría crítica de la sociedad de una profunda honradez intelectual, lo que no es poco. Como todo buen intelectual, 
sólo comprometido con la denuncia de la injusticia venga de donde venga, Santos es antes que nada un extraordinario lector y aquí radica la fuerza y pujanza de su teoría: mostrar las insuficiencias de las anteriores.

El hecho de haber realizado mucho trabajo de campo le ha puesto ante situaciones que le han vacunado contra cualquier enfermedad habitual entre otros filósofos: reduccionismo, optimismo, ingenuidad, etc.. Desde las primeras líneas, el lector sabe que la realidad social es poliédrica y que no hay analista que pueda estudiarla por completo, así se presenta el primer desafío a la razón. Porque lo que está en juego en la obra de Santos es encontrar una razón que no claudique ante la realidad pero que tampoco la reduzca a meras ideas, una razón débil. Y esto conviene aclararlo.

La auténtica razón postmoderna es débil no porque se arrodille ante los hechos o porque declare que todo vale; la razón postmoderna es débil porque el sujeto humano es finito. Y sólo desde esta finitud se entiende el optimismo trágico que recorre su obra. La historia es apropiación de posibilidades, de acuerdo, pero no sabemos siempre si éstas son las adecuadas para conseguir el principal objetivo: una vida más digna. No debe olvidarse que el camino al infierno está empedrado de buenas intenciones; y de ahí que el sentimiento trágico sea el soporte de toda la obra: la posibilidad del fracaso.
Santos inicia su crítica a la sociedad actual incidiendo en dos instituciones que condicionan todas las demás: la ciencia y el derecho. ¿Por qué éstas dos? Porque mediante ellas se ha pretendido ordenar la naturaleza y la sociedad. Pero ahora la pregunta es qué tipo de orden se ha conseguido. Y resulta claro que ese orden no es sino opresión. Con esto no quedan descalificados ni la ciencia ni el derecho, sino los intereses perversos que se esconden tras estas instituciones que de espejos se han transformado en estatuas. Lo que se denuncia es que sólo el conocimiento científico técnico sea el único conocimiento válido, y que sólo el derecho estatal sea el único capaz de ordenar la sociedad. Pero una razón "fuerte" ¿no exige que esto sea así? ¿No son el control y la predicción dos aspectos de la razón "fuerte"? ¿¿No está la idea de Progreso detrás de ésta razón? ¿Progreso de quién y de qué? Afirmar que el conocimiento científico es el único, no tiene nada de científico; afirmar que el derecho estatal moderno es el único, no tiene nada de jurídico. Sólo desde una brutal simplificación de la realidad pueden hacerse semejantes afirmaciones. ¿Puede el conocimiento científico anticipar el paradigma hacia el que nos dirigimos? ¿Puede por lo menos indicarnos algunos elementos que lo perfilarán? El recurso a la ingeniería social no puede ser la solución. Así la autocrítica es el punto más fuerte de la teoría de Santos.

¿Por qué hablar de autorreflexividad? Para evitar que la teoría 
crítica devenga ideología. La autorreflexividad permite el perfeccionamiento teórico e impide a la vez la cosificación o reificación de los conceptos. Y esto nos lleva de nuevo a la complejidad de la realidad social, una realidad que genera más realidad. ¿Cómo abordarla? Con una razón débil, débil porque siempre va a ser superada por la realidad, fuerte porque acepta el desafío. ¿En qué se traduce esta complejidad? Éste es otro de los puntos más atractivos de la teoría de Santos.

Se traduce en la diversidad de grupos humanos, en la diversidad de saberes y en la diversidad de órdenes. El reconocimiento de esta riqueza destierra cualquier pretensión de "universalismo" para dar paso a la interculturalidad y a la traducción como aumento de experiencia. Y así es porque el cierre grupal no tiene cabida en la obra de Santos, por eso las "comunidades ameba" como comunidades abiertas, resisten mejor a los intentos de asimilación o de colonización al incrementar su ritmo vital con la de otros grupos. Y esto no es relativismo, no todas las prácticas de los distintos grupos son respetables, es reconocer un criterio más amplio de la verdad, como mayor apropiación de la realidad. Por eso la verdad es para Santos retórica, prefiere lo razonable, lo permanentemente inconcluso, a lo racional, lo perfectamente definido para siempre.

Hay otro aspecto que, si bien no ha sido desatendido por otras teorías, no ha sido estudiado con la suficiente profundidad: la relación Norte-Sur. Decía el poeta Benedetti que el Sur también existe y no le faltaba razón. El eurocentrismo está todavía tan afincado en el pensamiento actual que impide ver con rigor la realidad. Pudiera decirse que es la ideología más peligrosa de todas porque en ella se gestan gran parte de los problemas que hoy nos afectan. A veces lo evidente no lo es tanto y hay que recordarlo: hay un Norte porque hay un Sur; y hay un Sur porque hay un Norte. Es decir, que uno no se entiende sin el otro. Es curioso que se hable de teorías como sistemas y se pase por alto este hecho. Decíamos que en "La crítica de la razón indolente", Santos no mencionaba a W. Benjamin, y no se puede comprender bien esta obra si no la vemos atravesada por esa frase que el trágico filósofo alemán repetía: todo monumento de cultura lo es también de barbarie. No son dos monumentos, es el mismo, y esto es de gran relevancia porque se denuncia expresamente al Norte como generador de barbarie. No son ya el Norte civilizado y el bárbaro Sur, el Sur es lo que el Norte no quiere ver porque no verse reflejado. No quiere ver porque el Sur le devuelve su barbarie y le obligaría a poner en cuestión muchos de sus "logros". Esto no es nuevo. Quien quiera entenderlo sólo tiene que leer a Tucídides — "La guerra del Peloponeso" para comprender que el esplendor de la democrática Atenas del siglo $\checkmark$ se sustentaba en la esclavitud y en el control despótico que ejercía 
en la Liga de Delos. De ahí que ese conocimiento prudente para una vida decente tengamos que buscarlo en las ruinas que encontraremos excavando, en lo que la civilización marginó o condenó. Parece pues que no va a ser el hombre "civilizado" el modelo a seguir. ¿Quién entonces?

Siguiendo con la metáfora de las ruinas, podemos encontrar una influencia de la teoría del "sujeto" en la obra de Deleuze y Guattari, tampoco mencionados por Santos. En "El Anti-Edipo" ambos autores recorren críticamente la obra de Freud y Lacan para concluir entre otras cosas que el inconsciente no es sólo una instancia opresiva sino también liberadora. $Y$ esto es así porque de una conciencia diseñada por el poder, del hombre "civilizado" no puede brotar ningún principio liberador, lo nuevo no está en ella. Si esto es así, tendríamos que ver el inconsciente como el ámbito en el que se encuentran sepultadas nuestras propias ruinas, deberíamos excavar en él, pues en él se hallan las fuerzas, los impulsos que nos permiten crearnos y recrearnos. Por eso también hablaremos de subjetividades débiles, porque nunca son definitivas, porque están abiertas a los cambios, porque en su debilidad está la fuerza para oponerse a los centros de poder.

Para concluir, podría decirse que la obra de Santos es original por la lectura inteligente de otros autores, lectura que le permite dar entrada a conceptos tomados de otras esferas: la cartografía, la fotografía, la pintura, de la navegación, etc.. Quizá sea la más universalista de todas pues está escrita desde la perspectiva de los olvidados y marginados. La obra de Santos hoy es simplemente imprescindible.

\section{Bibliografía}

-. B. SANTOS (2003) Crítica de la razón indolente, Desclée

-. B. SANTOS (2005) El milenio huérfano, Trotta

-. AGAZZI, E. (2000) Filosofía de la naturaleza (capítulo $1^{\circ}$ ), FCE

-. AGOSTO, P. (2000) (Wallerstein y la crisis del Estado-nación, Campo de ideas

-. ARENDT, H. (2005) La condición humana, Paidós
-. BAGÚ, S.: (1997) Catástrofe política y teoría social, Siglo XXI

-. BARCELLONA, P.: (1996) Postmodernidad y comunidad, Trotta

-. BARTHES, R.: (2002) Mitologías, Siglo XXI

-. BARTRA, R.: (2004) El duelo de los ángeles, FCE

-. BAUMAN, Z. (2000) La globalización, FCE 
-. BAUMAN, Z. (2004) Ética posmoderna, Siglo XXI

-. BAUMAN, Z.: (1997) Modernidad y holocausto, Ed. Sequitur

-. BERLIN, I.: (2002)La traición a la libertad, FCE

-. BERLIN, I.: (1974) Libertad y necesidad en la historia, Revista de Occidente

-. BERLIN, I.: (1992) El fuste torcido de la humanidad, Ed. Península

-. BERLIN, I.: (1978) Conceptos y categorías, FCE

-. BERMEJO, D.: (2005) Posmodernidad, pluralidad, transversalidad, Anthropos

-. BILBENY, N.: (1995) El idiota moral, Anagrama

-. BOBBIO, N.: (2005) El futuro de la democracia, FCE

-. BOBBIO, N.: (2006) Estado, gobierno, sociedad, FCE

-. BOBBIO, N.: (2006) Liberalismo y democracia, FCE

-. BOBBIO, N.: (2001) Ni con Marx ni contra Marx, FCE

-. BOFF, L.: (2002) El despertar del águila, Trotta

-. BOFF, L.: (2002) El águila y la gallina, Trotta

-. BURGOS, E.: (2005) Me llamo Rigoberta Menchú y así me nació la conciencia, Siglo XXI

-. CALVET, L. J.: (2005) Lingüística y colonialismo, FCE

-. CAPELLA, J. R.: (2001) Fruta prohibida, Trotta

-. CASSIRER, E.: (1984) La filosofía de la llustración, FCE
-. CORTINA, A.: (1986) Crítica y utopía: la Escuela de Francfort, Cincel

-. CRESPI, F.: (1997) Acontecimiento y estructura, Nueva Visión

-. DíAZ, E.: (1999) Posmodernidad, Biblos

-. DUSSEL, E.: (1998) Ética de la liberación, Trotta

-. ELIAS, N.: (1989) El proceso de la civilización, FCE

-. ELLACURÍA, I.: (1999) Filosofía de la realidad histórica, UCA

-. FARIÑAS DULCE, M. J.: (2005) Mercado sin ciudadanía, Biblioteca Nueva

-. FITZPATRICK, P.: (1998) El mito del derecho moderno, Siglo $\mathrm{XXI}$

-. FORNET - BETANCOURT, R.: (2001)La transformación intercultural de la filosofía, Desclée

-. FORNET - BETANCOURT, R.: (2003) Culturas y poder, Desclée

-. FORNET - BETANCOURT, R.: (2003) Resistencia y solidaridad, Trotta

-. FORNET - BETANCOURT, R.: (1992) Estudios de Filosofía Latinoamericana, UNAM

-. FOUCAULT, M.: (2002) Defender la sociedad, FCE

-. FREIRE, P.: (2005) Pedagogía del oprimido, Siglo XXI

-. GLOVER, J.: (2001) Humanidad e inhumanidad, Cátedra

-. GONZÁLEZ FABRE, R.: (2005) Ética y economía, Desclée 
-. HARVEY, D.: (2004) La condición de la posmodernidad, Amorrortu

-. HORKHEIMER, M.: (2002) Crítica de la razón instrumental, Trotta

-. KONSTANTINOV, F. V.: (1963) EI materialismo histórico (capítulos $1^{\circ}$ y $\left.6^{\circ}\right)$, Grijalbo

-. LANCEROS, F.: (2006) La modernidad cansada, Biblioteca Nueva

-. LÖWITH, K.: (1956) El sentido de la historia. Implicaciones teológicas de la filosofía de la historia, Aguilar

-. LÖWY, M.: (2005) Walter Benjamin. Aviso de incendio, FCE

-. LYOTARD, J. F.: (1987) La condición postmoderna, Ed. Cátedra

-. MACPHERSON, C. B.: (1979) La teoría política del individualismo posesivo, Fontanella (Trotta)

-. MANNHEIM, K.: (1958) Ideología y utopía, Aguilar (FCE)

-. MATE, R.: (2006) Medianoche en la historia, Trotta

-. MATE, R.: (1990) Mística y política, Verbo Divino

-. METZ, J. B.: (2002) Dios y tiempo. Nueva teología política, Trotta

-. MORO, T.: (2004) Utopía ("Las relaciones públicas entre los utopianos"), Alianza

-. MUGUERZA, J.: (1986) La razón sin esperanza, Taurus

-. O'GORMAN, E.: (2006) La invención de América, FCE

-. PEWZNER, E.: (1999) El hombre culpable. La locura y la falta en Occidente, FCE
-. POLANYI, K.: (1989) La gran transformación, La Piqueta

-. QueVEDO, A.: (2001) De Foucault a Derrida, EUNSA

-. RICOEUR, P.: (1995) Teoría de la interpretación, Siglo XXI

-. SALAZAR BONDY, A.: (1988) ¿Existe una filosofía de América latina?, Siglo XXI

-. SÁNCHEZ RUBIO, D.: (1999) Filosofía, derecho y liberación en América latina, Desclée

-. SEBASTIÁN, L.: (1999) El rey desnudo, Trotta

-. SERRANO CALDERA, A.: (2004) Razón, derecho y poder, Hispamer

-. SCAVINO, D.: (2000) La filosofía actual, Piados

-. SOBRINO, J.: (2003) Terremoto, terrorismo, barbarie y utopía, UCA

-. STIGLITZ, J.: (2006) El malestar en la globalización, Taurus

-. SUBIRATS, E.: (1994) El continente vacío, Anaya

-. SUBIRATS, E.: (1981) La ilustración insuficiente, Taurus

-. TODOROV, T.: (1991) Nosotros y los otros, Siglo XXI

-. TODOROV, T.: (1989) La conquista de América. El problema del "otro", Siglo XXI

-. TOURAINE, A.: (2000) Crítica de la modernidad, FCE

-. VILLORO, L.: (1997) El poder y el valor, FCE

-. WALLERSTEIN, I.: (2004) Análisis de sistemas - mundo, Siglo XXI 


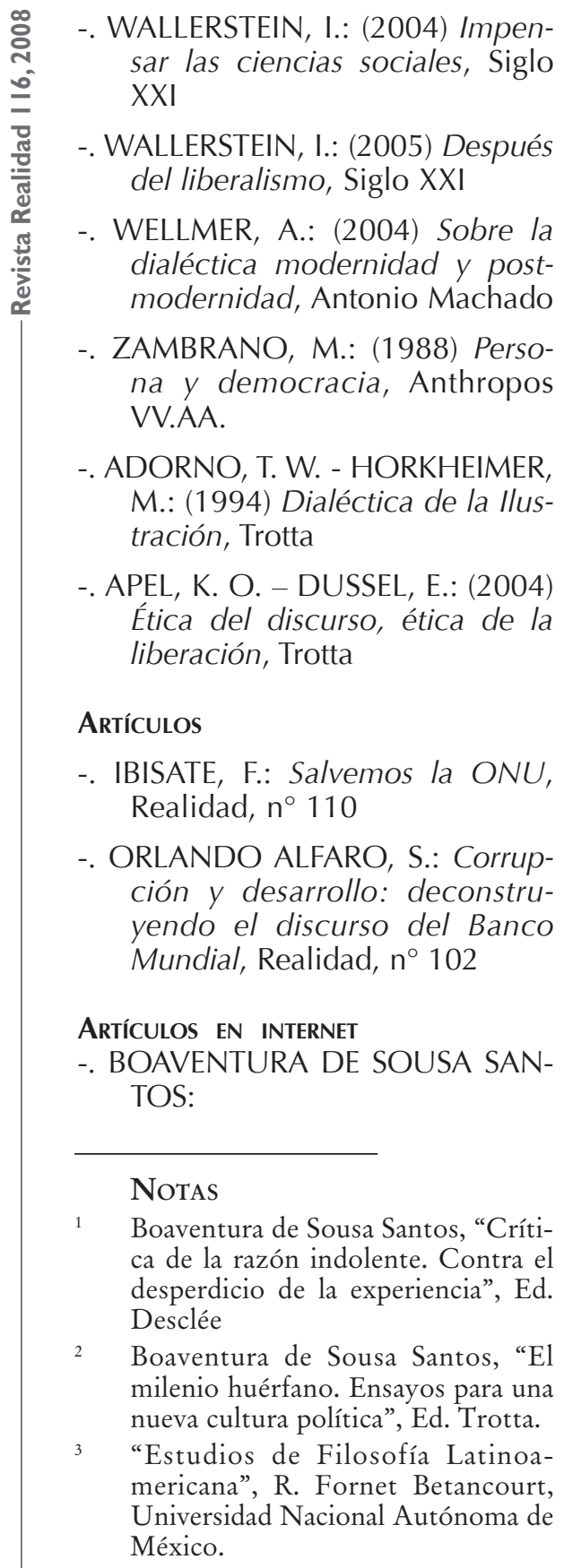

La transición postmoderna: politica y derecho

Democracia de alta intensidad

Globalización y democracia

Renovar la teoría crítica y reinventar la emancipación social

-. BORÓN, A.: Después del saqueo: el capitalismo latinoamericano a comienzos del nuevo siglo

-. CASTRO GÓMEZ, S.: Ciencias sociales, violencia epistémica y el problema de la invención del "otro"

-. FARIÑAS DULCE, M. J.: La "ficción" en la teoría jurídica de Hans Kelsen

-. FARIÑAS DULCE, M. J.: Las asimetrías de la globalización y los movimientos de resistencia global

-. FORNET BETANCOURT, R.: Por una nueva filosofía popular

-. FORNET BETANCOURT, R.: La interculturalidad como alternativa a la violencia

-. HINKELAMMERT, F.: La globalidad de la tierra y la estrategia de la globalización

4 "Porque lo cierto es que los hispanoamericanos estamos en el caso de existir inauténtico: vivimos desde un ser pretendido, tenemos la pretensión de ser algo distinto de lo que somos y lo que podríamos quizá ser, o sea, vivimos alienados respecto a la propia realidad que se ofrece como una instancia defectiva, con carencias múltiples, sin integración y por ende sin vigor espiritual.” ( A. Salazar Bondy“, ¿Existe una filosofía 
de nuestra América?”, p. 83, Siglo XXI)

5 "Al fin y al cabo, la reflexión crítica y quizá toda forma viva de pensamiento sólo comienza realmente allí donde el sentido de las palabras se vuelve extraño, incómodo y sospechoso, y donde se pone en cuestión sus significados, sus usos institucionalizados por las costumbres, por las organizaciones sociales o también por los diccionarios" (J. Subirats, "La ilustración insuficiente”, p. 15, Ed. Taurus)

6 "La filosofía tiene pues en Hispanoamérica una posibilidad de ser auténtica en medio de la inautenticidad que la rodea y la afecta: convertirse en la conciencia lúcida de nuestra condición deprimida como pueblos y en el pensamiento capaz de desenmascarar y promover el proceso superador de esta condición. Ha de ser entonces una reflexión sobre nuestro status antropológico o, en todo caso consciente de él, con vistas a su cancelación. Una reflexión aplicada al lenguaje o a las cosas, al conocimiento o la conducta, pero siempre antropológicamente relevante como autoanálisis. Esto quiere decir que una buena parte de la tarea que tiene pendiente nuestra filosofía es destructiva-a la larga destructiva también de su entidad actual como pensamiento alienado. Porque debe ser una conciencia canceladora de prejuicios, mitos, ídolos, una conciencia apta para develar nuestra sujeción como pueblos y nuestra depresión como seres humanos: en consecuencia una conciencia liberadorade las trabas que impiden la expansión antropológica del hispanoamericano que es también la expansión antropológica de toda la especie." (A. Salazar Bondy, ibidem, pgs. 90 -91)

7 Franz Rosenzweig, "La Estrella de la Redención”, Ed. Sígueme.

8 Reyes Mate, "Memoria de Occidente. Actualidad de pensadores judíos olvidados", Ed. Anthropos.
Véase la nota 5.

10 "Educación moral, postmodernidad y democracia”, p. 109, Ed. Trotta

11 Amalia Quevedo, "De Foucault a Derrida”, EUNSA.

12 Diego Bermejo, "Posmodernidad: pluralidad y transversalidad”, Ed. Anthropos.

13 Ibidem. P. 19

14 "La filosofía de la Ilustración ha fracasado precisamente cuando y donde pudo celebrar sus triunfos. Aquello que legitimaba históricamente su cometido, la supresión de la angustia de los individuos frente a los poderes de la naturaleza y su liberación de los poderes y constricciones sociales, ha sido reducido a lo que en un principio, se había determinado como su medio: el conocimiento científico de la realidad y el poder que de él emanaba sobre la naturaleza y la sociedad. El espíritu de las nuevas ciencias, proclamado como la supervivencia individual y de la libertad social, fue objetivado en una nueva forma de institución absoluta: la del conocimiento por el conocimiento, y del progreso de la ciencia y de la técnica como fin en sí mismo y principio absoluto. La condición que justificaba su importancia social, la conservación de la vida frente al poder, fue olvidada." (J. Subirats, ibidem, p. 131)

15 "La transición postmoderna. Derecho y política", p. 237

16 "Lo grave de esos mundos irreales no es que en cuanto "representaciones" substituyan al mundo real, sino que esos mundos ponen en marcha sendos tipos de actividades prácticas, igualmente extrañas a la realidad, pero con las que tratamos de configurar el mundo." (Reyes Mate, ibidem, p. 133)

17 "La única forma de que una conciencia social crítica conserve la libertad de pensar que las cosas podrán ser alguna vez de otro modo es que las cosas hayan podido ser de otro modo, que se rompa la pretensión 
esferas específicas y separadas con competencias propias, tal como se ha desarrollado en la modernidad; razón correspondería a la competencia operativa en el ámbito global de la racionalidad y a la competencia analítica de las relaciones entre las distintas esferas." Ibidem, p. 17

G. Scholem, comentando la obra de F. Rosenzsweig, se preguntaba: " $¿ E s$ que acaso todo puede ser pensado?"

27 Ibidem, p. 75

Ibidem, p. 77

Ibidem, p. 81

"Totalidad es una idea regulativa, no un concepto. No es un objeto de conocimiento, sino una perspectiva; no es una categoría, es una idea. (...) El todo es inacabable, ilimitable, siempre ampliable. Al todo pertenece una dialéctica de resistencia a la concreción vía ampliación, ya que cualquier objetivación del todo sería a su vez un elemento nuevo del todo. Lo que implica que una tematización correcta de la totalidad, adecuada a su lógica y dinámica internas, será la que la considere como inconclusa, abierta e ilimitable ". (Ibidem, p. 86)

31 Ibidem, p. 92.

32 Ibidem, pgs. 106-107

33 Ibidem, p. 109

Ibidem, pgs. 110 - 124

35 "Las verdaderas crisis son aquellas dificultades que no pueden ser resueltas dentro del marco del sistema, sino que deben resolverse por fuera y más allá del sistema histórico del cual las dificultades históricas son parte. Para usar el lenguaje de las ciencias naturales, lo que sucede es que el sistema se bifurca, esto es, encuentra que sus ecuaciones básicas pueden ser resueltas de dos modos muy diferentes. Podemos traducir esto a un lenguaje cotidiano diciendo que el sistema se enfrenta a dos soluciones alternativas para la crisis, 
ambas intrínsecamente posibles. (...) Puesto que el sistema existente ya no puede funcionar adecuadamente dentro de los parámetros definidos, tomar una decisión de cómo abandonar el sistema, sobre el sistema o sistemas futuros que han de construirse es inevitable. (...) Podemos llamar a esto un período de transición.(...) El sistema mundo moderno en el que vivimos, el de una economía mundo capitalista, se encuentra precisamente en una crisis semejante, y lo ha estado durante ya un tiempo." (Immanuel Wallerstein, "Análisis de sistemas - mundo", pgs. 105-6. Ed. Siglo XXI). Este es el punto de arranque de la obra de Santos, el cambio como apropiación de posibilidades." Al construir el sistema (o sistemas) sucesor del existente, debemos optar por un sistema jerárquico que otorga o permite privilegios de acuerdo con una jerarquía del sistema, como quiera que sea determinado (incluyendo méritos meritocráticos), o por un sistema relativamente igualitario y democrático. (...) Necesitamos primero que todo intentar comprender qué es realmente lo que está sucediendo. Necesitamos después decidir en qué dirección queremos que se mueva el mundo. Y debemos finalmente resolver cómo actuaremos en el presente de modo que las cosas se muevan en el sentido que preferimos." (Ibíd. Pgs121-2).

36 "La transición postmoderna: derecho y política”, B. Santos, Artículo en internet, Cervantes virtual.

El paradigma epistemológico dominante ya fue puesto en cuestión años atrás por el mismísimo Husserl en "La crisis de las ciencias europeas" y que Javier San Martín apunta: "No existe un primer Husserl idealista y un segundo que atemperaría tal idealismo por la consideración de la historia y de la realidad concreta del hombre. Por el contrario, el movimiento del pensamiento del

pensamiento de Husserl es un único movimiento en el que ciertamente hay etapas de desarrollo o correción de conceptos, pero siempre al servicio de un ideal que mueve toda su filosofía: dar una respuesta precisamente a la crisis de las ciencias; crisis que no es sino la expresión de otra crisis más profunda y preocupante, a saber, crisis de la humanidad europea, y por la hegemonía y transcendencia mundial de esta crisis, crisis en definitiva de la humanidad como especie. La fenomenología de Husserl es el intento de pensar la crisis europea, es decir, de descubrir sus raíces y de formular las condiciones que debe cumplir cualquier solución de esta crisis si ha de ser una verdadera solución.”(“Antropología y filosofía”, pg 68, Verbo Divino)

38 derno" en el sentido que Rubio Carracedo le confería. Es un modo 
rrollo, modernización, revolución, reformismo. En suma, espera con esperanza. Hoy vivimos un tiempo en el que, para la gran mayoría de la población mundial, esta discrepancia se invirtió; las experiencias actuales son probablemente muy difíciles pero las expectativas son todavía peores. Es decir, la idea de que si hay una reforma de la salud, de la seguridad social o de la educación, no es para mejorar sino para empeorar. Por eso hoy la gran mayoría de la población mundial espera sin esperanza. Pero no es que las expectativas sean negativas, es que para una gran parte de la población mundial ni siquiera hay expectativas. Hoy tenemos un colapso total de expectativas: quien come hoy no sabe si comerá mañana; quien está vivo hoy puede estar muerto mañana; quien envió a su hijo a la escuela este año, no sabe si lo podrá enviar el año entrante. Este colapso de expectativas es el colapso de la sociedad misma, el colapso del contrato social, es el contrato de las poblaciones desechables, son procesos de exclusión irreversibles. La gente deja de ser ciudadana y es el paso de la sociedad civil a lo que yo llamo sociedad incivil: mucha gente vive en la desigualdad y habiendo un colapso total de expectativas, depende de fuerzas poderosas que escapan a su control. (...) Corremos el riesgo de vivir en sociedades que son políticamente democráticas pero socialmente fascistas." (B. Santos, "Democracia de alta intensidad", CNE, pgs. 53-4)

45 En 1933, W. Benjamín escribía: "La cosa está clara: la cotización de la experiencia ha bajado y precisamente en una generación que de 1914 a 1918 ha tenido una de las experiencias más atroces de la historia universal. Lo cual no es quizá tan raro como parece. Entonces se pudo constatar que las gentes volvían mudas del campo de batalla. No enriquecidas sino más pobres en 
cuanto a experiencia comunicable. (...) Pobreza de experiencia: no hay que entenderla como si los hombres añorasen una experiencia nueva. No, añoran liberarse de las experiencias, añoran un mundo entorno en el que puedan hacer que su pobreza, la externa y por último la interna, cobre vigencia tan clara, tan limpiamente que salga de ella algo decoroso. (...) Nos hemos hecho pobres. Hemos ido entregando una porción tras otra de la herencia de la humanidad, con frecuencia teniéndola que dejar en la casa de empeño por cien veces menos de su valor para que nos adelanten la pequeña moneda de lo "actual"." ("Discursos interrumpidos, 1”, Taurus)

En esta extraña forma ligüística es porque los postmodernistas buscaban un modo de salir del dominio lingüístico que la ideología liberal tenía sobre nuestro discurso. Como concepto explicatorio, el postmodernismo es confuso, pero como doctrina anunciatoria el postmodernismo ciertamente da en el blanco porque sin duda nos movemos en dirección a otro sistema histórico. El sistema mundial moderno está llegando a su fin.” (i. Wallerstein, "Después del liberalismo”, p. 146, Ed. Siglo XXI) Ibíd. P. 39

$47 \quad$ Ibíd. P. 50

48 Ibíd. P. 50

49 "Dedicó toda su vida (Helvetius, siglo XVIII) a la busca de un solo principio que definiera la base moral y diese verdadera respuesta a las preguntas acerca de cómo debía fundarse la sociedad y cómo debía vivir el hombre y adónde debía ir y qué debía hacer, con el mismo grado de autoridad científica que Newton había implantado en el ámbito de la física. Y Helvetius creyó haberlo encontrado y, por tanto supuso que él era el fundador de una gran ciencia nueva, con la cual podría poner finalmente orden a este vasto caos

político y moral. En pocas palabras, creyó ser el Newton de la política." (I. Berlin, "La traición de la libertad”, pgs. 31-2, FCE)

50

51

Ibíd. P. 67

Para F. Rosenzsweig, toda la filosofía occidental ha sido idealista. Véase "La estrella de la redención", Ed. Sígueme.

52 En este punto, conviene hacer una precisión. Leamos la Regla VIII: "Si en la serie de cosas que se han de investigar se presenta algo que nuestro entendimiento no puede intuir suficientemente bien, allí es preciso detenerse, y no se deben examinar las demás cosas que siguen, sino abstenerse de un trabajo superfluo.”(R. Descartes, "Reglas para la dirección del espíritu”, p. 107, Alianza) No parece pues que se trate de aplicar el mismo método para cualquier campo de conocimiento, sino de abstenerse de conocer aquellos ámbitos de los que no es posible extraer ideas claras y distintas. Así la Historia pertenecería a éstos últimos y Descartes la desatendió. Habría que esperar a Vico.

53 I. Berlin, refiriéndose a los descubrimientos revolucionarios de Newton y Galileo, escribe: "Existía por primera vez la posibilidad de organizar una masa caótica de datos procedentes de la observación en un sistema único, coherente y perfectamente ordenado. ¿Por qué no habrían de aplicarse con igual éxito los mismos métodos a las cosas humanas, a la moral, a la política, a la organización de la sociedad? ¿Por qué habría que suponer que los hombres pertenecen a un orden ajeno al sistema de la naturaleza? (...) ¿Por qué no se podía crear una ciencia o unas ciencias del hombre y aportar también ahí soluciones tan claras y seguras como las obtenidas por las ciencias del mundo externo?." ("El fuste torcido de la humanidad”, p.51, Ed. Península) 


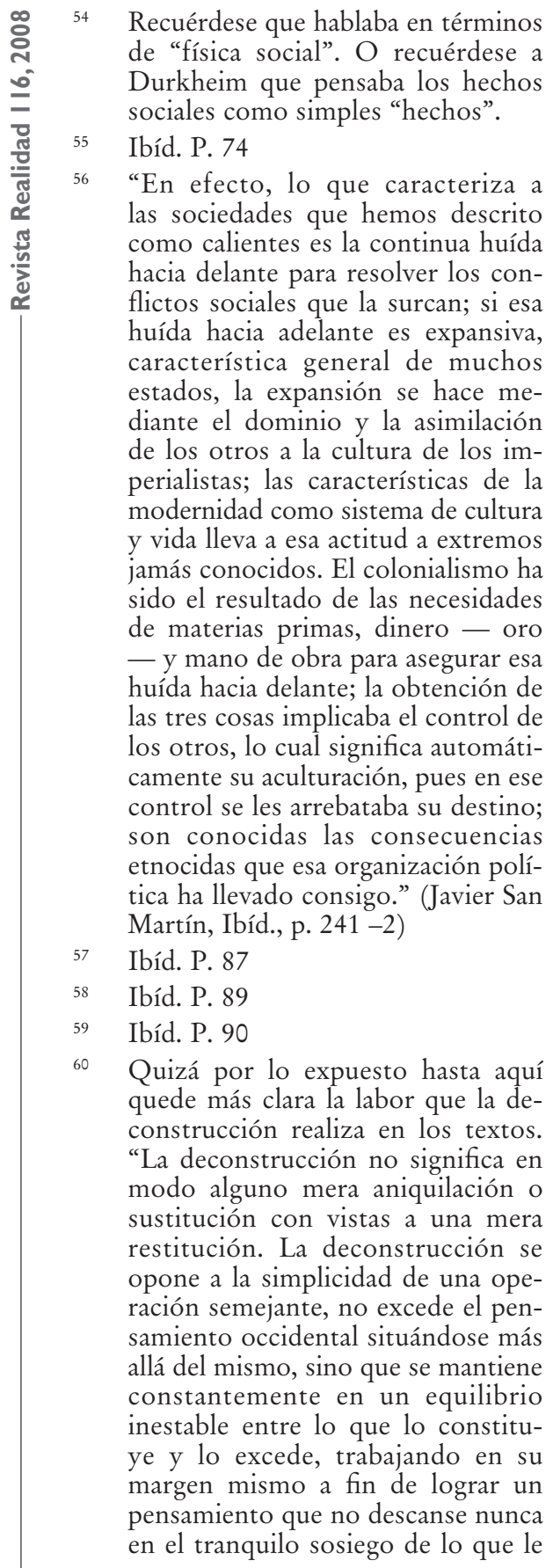

es familiar. Para ello es preciso que la estrategia se desdoble, que realice un gesto doble, que si bien, por una parte implica el rechazo violento de los valores metafísicos tradicionales, por otra parte procede a una lectura atenta y vigilante del pensamiento occidental, a una lenta y minuciosa labor estratégica de desplazamiento de de efectos y preocupaciones, de cambio de terreno, pero también de actitud, de tono, de estilo, en una palabra, de escritura que planteándose de una forma directa las bazas filosóficas e ideológicas del trabajo puramente intelectual, introduce un germen de insatisfacción incesante y de constante desasosiego en el apacible confort y familiaridad en la que se encuentra actualmente el pensamiento." ( C. De Peretti, "J. Derrida.Texto y deconstrucción “, p. 21, Ed. Anthropos) ferencias amplias, todos los autores interesados por el conocimiento del sujeto coinciden en la categoría de la alienación. La alienación psicótica sería el resultado de una alienación socioeconómica y sociopolítica. Para Laing, "la ezquizofrenia es el posible resultado de una dificultad fuera de lo común en ser persona entera con el otro y el de no compartir la manera del sentido común de experimentarse a uno mismo en el mundo. Dado que vivimos en lo que Laing llama "inseguridad ontológica", el sujeto sólo tiene dos salidas. La primera es romper con el mundo y así el sujeto se comporta como una fortaleza vacía. La segunda, desarro- 
llar una doble personalidad - el yo dividido - de tal manera que su contacto con el mundo si bien no se interrumpe, le resulta ajeno. ¿Dónde queda esa subjetividad "fuerte" de la modernidad? (J. San Martín, Ibíd., cap. V)

Ibíd. P. 138

"Con frecuencia hay mucha diferencia entre la voluntad de todos y la voluntad general; ésta sólo mira al interés común, la otra mira al interés privado, y no es más que una suma de voluntades particulares; pero quitad de esas mismas voluntades los más y los menos que se destruyen entre sí, y queda por suma de las diferencias la voluntad general." (J.J. Rousseau, "El contrato social”, p. 52, Alianza). "La voluntad general no cambia según el número de votantes. Lo que generaliza la voluntad es menos el número de votantes que el interés común que los une. La voluntad general es inalterable en su esencia, no está vinculada al voto de éste o de aquél, ni aún a la voluntad de todos, que como hemos visto, puede estar en contradicción con ella". (B. Groethuysen, "J.J. Rousseau", p. 100, FCE)

"Su clásica defensa del poder absoluto no será la defensa del monarca autócrata que hacían los partidarios de éste, basada en la proclamación del derecho divino; será una tesis utilitaria a la que llegará por el camino del individualismo burgués y laico, y tendrá como objetivo la conservación de la paz en interés de los integrantes de la sociedad civil." ("Empirismo e Ilustración inglesa", J.C. García Borrón, p. 64, Ediciones Pedagógicas)

"Que un hombre esté dispuesto, cuando otros también lo están como él, a renunciar a su derecho a toda cosa en pro de la paz y defensa propia y se contente con tanta libertad contra otros hombres como consentiría a otros hombres contra él mismo.” (T. Hobbes, “Leviatán”, cap. 14, Editora Nacional)

73 Ibíd. P. 150

74 "Pues la misma ley de la naturaleza que mediante este procedimiento (el trabajo) nos da la propiedad, también pone límites a esa propiedad. (...) Todo lo que uno pueda usar para ventaja de su vida antes de que se eche a perder será lo que le esté permitido apropiarse mediante su trabajo. Mas todo aquello que excede lo utilizable, será de otros." (J.Locke, "Segundo Tratado", p.59, Alianza). ¿Está equivocado Santos? Son muchas las alusiones que hace Locke a la propiedad limitada, sin embargo él mismo reconoce que con la aparición del dinero, todo cambia.

75 C.B. Macpherson, "El individualismo posesivo”, p. 225-6, Fontanella.

76 Ibib. P. 158.

77 "El mismo concepto de dignidad humana se supedita a la forma de acceso a la producción y distribución de bienes. Sólo puede garantizarse en toda su dimensión, al igual que todos los derechos humanos, en función de ella. Luego ir en su contra supone el rechazo de la dignidad humana. Por tanto, el interés general objetivo y la oposición al principio de jerarquización imperante se transforma en una polarización entre quienes lo aceptan y quienes no lo aceptan. Los primeros son amigos y partidarios del sistema que respeta y proporciona la dignidad; los segundos enemigos y opositores. Esa negación llega, incluso, a convertirse en crimen ideológico porque va en contra de la humanidad. Quien cuestiona el orden, pierde su capacidad de ser sujeto de derechos y como consecuencia de su comportamiento peligroso, se le pueden suspender los derechos humanos.”(D. Sánchez Rubio, "Filosofía, derecho y liberación en América Latina”, Ed. Desclée, p. 255) 

al que la administración pública está sujeta. La lógica privada, que es casi siempre lógica de lucro, combinada con la ausencia de control democrático, no puede dejar de agravar las desigualdades sociales y políticas." (Ibíd. p. 197-8) "El estado fue el gran agente de interacciones no mercantiles. Pero desde los años 80 , la globalización neoliberal ha invertido totalmente esto. Hoy en día el estado es un agente de interacciones mercantiles. La privatización de los servicios públicos es exactamente esto, relaciones que no eran mercantiles y que ahora se están mercantilizando: la educación, la seguridad social, etc.. El Estado ha hecho esto debido a la presión global; el Estado que hasta entonces era considerado como una solución a los problemas, pasó a ser nuestro problema. La solución está entonces en la sociedad civil. Esta es una inversión total de una idea muy clara: que el estado no era el contrario de la sociedad civil, sino su espejo. Un Estado democráticamente fuerte podía crear una sociedad civil fuerte; un Estado democráticamente débil nunca crearía una sociedad civil fuerte. Pero al contrario, desde los años 80, la idea opuesta es la que domina: para que la sociedad civil sea fuerte es necesario que el Estado sea débil." (Santos, "Democracia de alta intensidad”, pgs. 54-5, véanse también pgs. 57-58)

84 Ibíd. P. 177

85 El hecho de que en esta fase el Estado Providencia sufra un deterioro no significa que no haya intervencionismo. Como bien apunta F. Hinkelammert: "Este anti - intervencionismo necesita para ser posible, una alta concentración del poder en el Estado. Para poder destruir al Estado intervencionista, hace falta un nuevo poder estatal mayor, que sea capaz de acallar los reclamos de intervenciones estatales. Disminu- 
yendo por tanto las intervenciones en el campo económico y social, suben más que proporcionalmente las actividades represivas estatales, los gastos en policía y ejército. "La represión policial libera, los gastos sociales esclavizan": este es el lema del nuevo estado anti - intervencionista que resulta ser en muchas partes simplemente un Estado policíaco." (“Crítica de la razón utópica”, Ed. Desclée, pgs. 168-9)

86 Ibíd. P. 178

87 "En el campo del derecho, cuando el fenómeno jurídico se concibe como mera forma o procedimiento, sucede que se absolutiza tanto esta dimensión que se transforma en la única realidad posible, ocultando otros elementos importantes, entre ellos, los procesos sociales y sus actores. Por este motivo, el DA (Derecho alternativo) de alguna manera critica el formalismo jurídico porque representa un modo de escamotear el contenido perverso que subyace en parte del ordenamiento jurídico. Priorizar y absolutizar la forma en la ciencia jurídica por encima del contenido implica una actitud ideológica e interesada de determinados sujetos hasta tal punto que incluso el problema de la vida humana pierde importancia. El derecho, como instrumento de poder que es, está muy vinculado al campo de lo político y lo económico. De ahí que intentar subrayar la autonomía y la neutralidad de las ciencias jurídicas supone despreocuparse de los procesos sociales en los que se inserta el propio derecho y además conlleva a su deslegitimación. Por esta razón no sólo se trata de situar la discusión en el interior del campo jurídico sino que sobre todo hay que relacionar y definir el derecho con el marco y el contexto socioeconómico en el que se ubica. No hay que ignorar el ámbito en el que se desarrolla el control del poder ni el espacio en el cual se manifiesta la capacidad de construir la realidad a favor de determinados intereses." (David Sánchez Rubio, "Filosofía, derecho y liberación en América Latina”, Ed. Desclée, p. 246-7)

88 W. Benjamín, "Sobre el concepto de historia”, Ed. Taurus.

Reyes Mate, "Medianoche en la historia”, Ed. Trotta, p. 146

Ibíd. P. 149

91 Ibíd. P. 209.

"Impensar las ciencias sociales", P. 3, Siglo XXI

93 Bajo la égida de la globalización, el paradigma neoliberal triunfa a costa de extender sobre sus críticos una epidemia de crisis y de imposibilidad de alternativas. Se dice que hay crisis de paradigmas pero resulta que es debido a que el neoliberalismo es el único paradigma posible. Paradójicamente, la democracia y los derechos humanos pasan a ser los principales baluartes con los que justificar políticas que, pese a implicar continuas cargas y violaciones sobre la dignidad de la mayoría de la población, tienen licencia para sacrificar vidas a favor de un desarrollo que sólo interesa a quienes conciben y aplican esas mismas políticas. Efectivamente, los derechos humanos se proclaman a costa de ser vulnerados.” (D. Sánchez Rubio, "Filosofía, derecho y liberación en América Latina", Ed. Desclée, p. 264)

$94 \quad$ "El análisis de los sistemas mundo es un llamado a construir una ciencia social histórica a la que no incomoden las incertidumbres de la transición, que contribuya a la transformación del mundo al iluminar las opciones sin recurrir a la muleta del triunfo inevitable del bien. El análisis de los sistemas mundo es un llamado abrir las persianas que nos impiden explorar muchos terrenos del mundo real. Dicho análisis no es un paradigma de las ciencias históricas, es un llamado a un debate sobre el paradigma." (E. Wallerstein, Ibíd. p. 277) 
refrenamiento y la distorsión de este proceso de cambio y al mismo tiempo las obstrucciones de las cuales el mundo ha cobrado conciencia en los últimos veinte años. El consenso posterior a 1789 respecto a la normalidad del cambio y las instituciones que engendró, ahora ha terminado al fin. Pero no en 1917, sino en 1968." (E. Wallerstein, Ibíd., p. 25)

Esta subjetividad, podría integrarse en lo que Deleuze llama pensamiento nómada. "El pensamiento nómada no afirma el principio de identidad, lo Mismo, sino que por el contrario afirma el principio de Diferencia, lo Otro, lo múltiple, lo disperso lo marginal.(...) El pensamiento nómada busca desvelar los simulacros y las máscaras de la razón occidental, lo Otro, que escapa al modelo ideal. Este pensamiento ya no presenta la presunta unidad de lo real, sino su anarquía, su dispersión y su diferencia. Procede al modo de las tribus nómadas, que no se reparten el territorio ni se fijan a él, que se dispersan." "De Foucault a Derrida", p. 116, Amalia Quevedo, EUNSA 